\title{
Is Job Quality Becoming More Unequal?
}

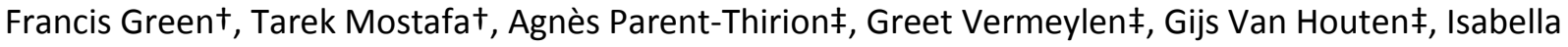
Bilettał and Maija Lyly-Yrjanainenł.

† LLAKES Centre, Institute of Education, London; ₹ European Foundation for Living and Working Conditions.

\begin{abstract}
.
This paper examines trends in non-wage aspects of job quality in Europe, with a focus on their dispersion as well as their level. Theories differ in their predictions for these trends, and on whether they expect national convergence. Data from the $5^{\text {th }}$ European Working Conditions Survey are used, in conjunction with earlier waves, to construct four indices of non-wage job quality, Work Quality, Work Intensity, Good Physical Environment and Working Time Quality. We track them from 1995 to 2010, across and within 15 European Union countries. The social corporatist countries had the highest Work Quality, and lowest dispersion for all four indices. While continuity is found, Work Quality and Work Intensity each rose in several countries, and Working Time Quality rose in most. The dispersion of Working Time Quality, Work Intensity and Good Physical Environment each fell in many countries; and there was little sign of national divergence.
\end{abstract}




\section{Introduction}

Much is known about how wages have grown or stagnated, and become more unequal across a range of countries though to differing extents, and about how these trends may be linked to changing technologies, work organization, labor market institutions and intensified global competition. It should also be illuminating, due to interest in the role of labor market institutions, to observe how job quality trends for areas other than wages vary across countries and between varieties of capitalism. Since the inception of the European Employment Strategy in the late 1990s there has been some emphasis in European policy discourse on the quality, as well as the quantity, of employment; and the link between job quality and well-being at work has entered as an ingredient of the advocated broader approach to the measurement of national well-being (Stiglitz et al., 2009: 49).

Yet changes in non-wage aspects of job quality across countries have been less well documented than the evolution of wages. There are studies of particular features, such as insecurity or intensification, usually in single countries, but few which take a perspective over a range of countries and multiple domains of job quality, and none which are able to present an up-to-date picture following the great recession of 2008-9. The aim of this paper is to examine trends in several non-wage aspects of job quality in Europe. We examine these trends in the light of existing theories and expectations about the evolution of job quality, taking the analysis up to 2010, and covering 15 countries across Europe. ${ }^{1}$

In line with developing practice we utilize an objective concept of job quality, which defines it as a set of features that help to meet job-holders' needs from work. This approach means that we include only variables characterizing jobs, leaving out those applying to individuals' lives or their preferences. ${ }^{2}$ Also omitted are variables capturing the labor market environment of jobs, such as the unemployment rate and the level of social protection. Thus our analysis is more focused than others using wider classes of variables, such as the International Labour Organisation's "decent work" index (Ghai, 2003; Bescond et al., 2003), or the "quality of employment" indices being developed by the United Nations Economic Commission for Europe (Körner et al., 2011). In addition to wages, job quality comprises the job's prospects (career prospects and job security), features conducive to a good work-life balance, and several intrinsic aspects of jobs - including the quality of the work itself, its physical environment and its pace or intensity, and the social relations at work (which can be supportive or abusive). ${ }^{3}$

While all of these features are captured to some degree in our data for 2010, not all are available over a sufficient time interval to permit an analysis of trends. Nevertheless, basing our analyses on successive waves at 5-year intervals of the European Working Conditions Surveys (EWCS), we are able to report for the first time on trends in multiple domains for which previously there has been little information.

Theory and previous literature generate contrasting predictions as to how the level and dispersion of job quality is thought to have evolved. There are optimistic predictions that job quality will have improved with economic growth, and that regulatory forces and workers'

\footnotetext{
${ }^{1}$ Among these countries, from 1994 to 2005 wage inequality rose to various extents in the UK, Netherlands, Germany, Finland, France and Sweden; while falling in Spain and Ireland (OECD Oberver, June 2007).

${ }^{2}$ Individual reports of well-being have been used to investigate criterion validity for the constructed indices of job quality.

${ }^{3}$ This framework is an adaptation of that set out in European Foundation (2002). Note that, unlike the "Laaken indicators" developed by the European Commission to support the European Employment Strategy, this framework demarcates job quality as conceptually separate from, even if related to, productivity (Green, 2006; Peña-Casas, 2009).
} 
demand will have reduced differences in working conditions; but these predictions are contested by those who emphasize the persistence of neo-Fordist labor processes, and are set against expectations that the inequality will have increased, derived from extrapolation of the theory and evidence on rising wage inequality. There are also different perspectives as to whether job quality trends are similar in many countries, or whether national differences in regulations and in labor market institutions have induced different paths of development. Both "varieties of capitalism" and "power resources" theories of how institutions affect the functioning of labor markets expect to find job quality differences between nations, and there is some evidence of better job quality in Nordic countries (e.g. Gallie, 2003). Discovering whether there are divergent paths of change provides a useful test of the importance of national-level institutions (Olsen et al., 2010).

We therefore focus on the dispersion as well as the level of non-wage job quality, and on the extent to which there may be divergent or convergent trends between countries. We first report on the construction of four job quality indices, covering work quality, work intensity, the physical environment of work, and features of working time conducive to a good worklife balance. We expect to find considerable continuity, but are also interested in the directions of change. To study dispersion we examine both the gaps between socio-economic groups, and the differences among individuals within countries. To study the levels we investigate mean values and how they evolve overall and within countries. For both the levels and the dispersion, the issue of convergence and divergence is studied by examining whether the variation across countries is narrowing or widening.

To set the context, Section 2 presents a brief overview of existing theories' expectations about the levels and dispersion of job quality dimensions. Section 3 notes the rather scarce previous evidence in this field, and we identify relevant questions about the evolution of job quality. Sections 4 and 5 focus on the data and on the construction of indices of job quality. Section 6 presents our findings about change over the 1995-2010 period, looking both at the overall sample and at individual countries. Section 7 gives our discussion of what the findings amount to.

\section{Theories of Change in the Level and Dispersion of Job Quality}

Theories about how job quality is expected to have changed in the modern era may be broadly divided into those that take a universal perspective, and those that emphasize differentiation across countries or across groups of countries with similar institutional regimes.

In the universal approach, it could be held that more affluent countries will have jobs of better quality, and that increasing affluence in the long term, signaled by rising GDP per capita, will be reflected in rising job quality. With jobs having multiple characteristics, an assumption of homothetic preferences would be enough to ensure that, as wealth rises, workers would choose to 'buy' improvements in all features that they value. ${ }^{4}$ If, however, production relations evolve as neo-Fordist, it remains possible that job quality could stagnate or decline, even while wages increased. Per contra, in a post-Fordist world, non-wage job quality features, such as autonomy and challenge, would be expected to rise as well as wages. In so far as one might expect to see the technologies behind these evolutions as ubiquitous, the trends in job quality could be expected to be common across countries.

\footnotetext{
${ }^{4}$ The substitution effect of rising hourly wages generates theoretical ambiguity; yet the long term has seen reductions in work hours in Europe, which is generally interpreted as the income effect exceeding the substitution effect.
} 
When the relative demand for skilled labor, bolstered by skill-biased technical change, outstrips the growth of supply, there is the further expectation that, just as there have been increasing wage returns to skill, so other aspects of job quality would become more unequal. This prediction is counterbalanced, however, when the predominant new technology leads to the automation of programmable manual and non-manual tasks previously important in middle-paid jobs, while complementing non-routine aspects of high-skill jobs. In this 'nuanced' theory of skill-biased technical change it is expected that there will be an asymmetric polarization of jobs: a relative growth in the number of jobs with low pay, relative to the number of jobs with middle-range pay, and the largest growth in high-pay jobs (Autor et al., 2003; Goos and Manning, 2006; Goos et al, 2010). Increased sub-contracting and outsourcing of jobs reinforce this tendency, because there is overlap in the jobs that can be automated or outsourced. If the non-routine content of jobs is associated to some extent with higher levels of task discretion, the relative growth of non-routine tasks at the lower end of the occupational spectrum would imply reductions in the inequality of this aspect of job quality; but the simultaneous growth of non-routine task content at the top end, where autonomy is already high, means that the prediction about the overall effect of technological change on the inequality of task discretion is ambivalent.

Organizational changes, such as the growth of teamwork, and the rise of "high-performance" management practices, also have substantive implications for job quality (examples are Osterman, 2000; Danford et al., 2008; Gallie et al., in press). To some extent these organizational changes are complements to technical change, and could be expected to affect jobs in all countries. However, organizational changes also reflect heterogeneous management cultures and choices, with the implication that job quality could change in different ways across countries and regimes (Rubery and Grimshaw, 2001).

Technical and organization changes may be biased, not only in terms of skill requirements, but also in their implications for other aspects of jobs that are important for job quality. For example, it has been argued that new technology is also effort-biased, in that the increments to productivity arising from innovation are disproportionately greater for those workers who put in greater levels of intensive effort (more effort in a given work-time) (Green, 2004). As new technology diffuses, this theory predicts that work intensification is likely to be widespread. Technology's effect on effort would also be predicted to be greater for those workers who were previously working below their physical and mental limits; hence we would expect a reduction in its dispersion.

Finally, one might anticipate some generalized changes in job quality in response to changing demands from workers and consumers. One pertinent example is the growing demand, following steadily increased female participation in the labor force in all countries, for jobs with characteristics that help to reach a work-life balance. Another is the impact of ageing and of rising education on the structure of services demanded.

In contrast to universal theories, other writers stress the influence of national-level institutions in affecting jobs, whether in respect of pay or of other aspects of job quality. The broad consequence is the expectation that there will be persistent differentiation across countries in distributions of job quality. In the varieties of capitalism framework (Hall and Soskice, 2001) it is hypothesized that job quality will vary across production regimes, and in particular be greater in coordinated market economies (CME) than in liberal market economies, since in the former employers' strategy is to commit to long-term employment relations. The implication is, not only better job security, but also better job quality in all dimensions, in the CMEs.

Coupled with this prediction from the perspective of the system of production, however, is 
the uneasy link with social reproduction systems: the greater probability of career interruptions for women leads, in CMEs, to gender gaps in job quality reflecting the segregation and segmentation that follows from employers' investment in firm-specific skills (Estevez-Abe, 2005). In production regime theories these ideas should apply to all CMEs, but in contrast the employment regime framework (sometimes referred to as the "Power resources" model) differentiates within the CMEs between social corporatist (also termed "inclusive") and dualist regimes (Gallie, 2007a; 2007b; Olsen et al., 2010). The distinctiveness of these regimes is driven by the nature and strength of trade unions, and the balance of power between labor and capital. With social corporatist regimes the state supports employment policies to promote good work opportunities across the population; whereas in dualist regimes the historical strength of the core male workforce of skilled long-term employees persists. In short, these institutional theories predict, not only that job quality is higher in CMEs than in LMEs, but (in the employment regime version) that job quality is more equally distributed in the social corporatist regimes found among the Nordic countries.

Production regime and employment regime models are less decisive about the pattern of change in job quality that is to be expected. ${ }^{5}$ If employment regimes persist, because they constitute an institutional equilibrium with self-reinforcing financial and employment systems, one might also expect a pattern of job quality change, with coordinated economies more resistant than liberal market economies to global competition. Other universal pressures for change, such as new technology, would also be differentially resolved. However, the stability of institutional regimes may be in question. ${ }^{6}$ In addition, across countries the different paces of institutional change or continuity could be expected to give rise to a varied pattern of change in job quality. As employment institutions evolve, reflecting in part a changing balance of power, one can expect to see differential change in job quality. Where trade unions have been most weakened, as for example in the United States or Britain, one would expect to see the greatest changes in both the levels and inequality of job quality.

Reinforcing this point, job quality in key domains reflects national regulations about working conditions, working time, wages, equal treatment, and health and safety. As a general rule, regulations can be expected to lower inequalities in job quality, in that it is primarily in the lower quality jobs where controls bite. Regulations develop at their own pace, towards either deregulation or re-regulation, varying across countries.

Yet, to some extent regulation patterns spread across countries through processes of demonstration and policy learning. An example is the case of smoking constraints in workplaces. Moreover, several labor market regulations in Europe stem from supra-national government: the European Union's Directives have had widespread implications for job quality across member states, as national governments are required to bring their own laws into line. In the last fifteen years, such directives have driven the adoption, or confirmation, of national regulations on working time (and associated paid holidays), rights to workplace representation, and fair treatment of part-time workers, workers on fixed term contracts, and most recently temporary agency workers. These supra-national regulatory influences imply both some equalizing forces within countries and some convergence between countries.

The extent of convergence or divergence between countries has been seen as something of a litmus test for the growing or declining importance of the 'universal' pressures on job quality. (Olsen et al, 2010). If the relative impact of institutions has been diminishing over time, it is

\footnotetext{
${ }^{5}$ Another limitation is that regime theories are focused on archetypal examples. The large majority of countries are different, not least the many southern European countries that resemble none of the three models.

${ }^{6}$ Thelen (2004), for example, poses a model of punctuated political equilibrium to account for the evolution of the skill formation insitutions in Germany and Britain.
} 
argued that countries would converge. By contrast, if institutions' role is becoming more important, then it is possible that countries' job qualities could diverge. We shall examine the evidence below. However, this test is asymmetric. A finding of divergence suggests an increasing role for institutions, relative to universal pressures, but the opposite finding of convergence leaves the case open. If institutional changes are in the same direction across countries, or if supra-national regulation is important, one could still expect to witness some degree of convergence.

Finally, theories of the overall level and distribution of aspects of job quality also have implications for job quality gaps between socio-economic groups. Universal technology pressures and supranational regulatory forces (for example, those that proscribe forms of discrimination) could be expected to narrow gender gaps, but national institutional differences, for example in the strength and policies of unions, could be expected to maintain and even widen patterns of differentiation.

In light of this brief overview of existing theories of workplace change, we can summarize the context for our examination of trends in the distribution of job quality as follows. It is expected that there is a positive relationship between job quality and per capita GDP, that the CMEs would tend to have higher job quality, and that in particular the inclusive CMEs would have the lowest levels of inequality in multiple dimensions. In so far as there is a generalized increased affluence in the economy, a diffusion of post-Fordist workplace regimes, and a widespread regulation of working conditions, rising job quality is expected; even so, technological change may also stimulate a widespread intensification of work effort. Rising returns to skill and/or universal de-regulation suggest that job quality will become more unequal in multiple dimensions, not just wages; but this prediction is also modified by the "nuanced" theory of technical change which emphasizes the survival of non-routine tasks in low-paid jobs, by increased demand for a better work-life balance, and by evolving regulation of important job features such as environmental hazard and working time. Above these generalized themes we also expect differentiation across regimes and countries, with the CMEs showing the greatest resistance to upward pressures on inequality. Evidence of divergence among countries would then be indicative of the maintained or increased importance of an institutional determination of job quality.

\section{Previous Quantitative Evidence About Changing Job Quality}

A commonality between all these theories is the expectation that some substantive change in the distribution of job quality is expected. Yet a further possibility is that theorists have overestimated the effect of transformations in the workplace on job quality. Institutional resilience and cultural persistence may limit the speed at which working conditions are altered, and perspectives of change could be based on a distorted perception of the past which gives a false impression of radical change. Past analyses and projections, for example, of an "end to work", or of a "Brazilianisation" of European labor markets, have proved very wide of the mark (Green, 2009; Fevre, 2007). Handel (2005), using General Social Survey evidence, finds substantive continuity in perceptions of job quality over almost a decade, and concludes that both optimistic and pessimistic schools may have overstated their case.

Whether this is a generalized finding deserves investigation on a broader scale. Hitherto, most evidence about change in job quality has focused on wages. Since 1980 wages have become much more unequal, but more so in some countries than others. Within Europe, Sweden, Germany, the Netherlands and the UK are all countries with widening differentials, but there was much more stability in France and Finland (OECD, 2008). For non-wage job 
quality features, some evidence is available for certain individual countries. Examples are Finland (Lehto and Sutela, 2005), the US (Schmidt, 2001; Kalleberg, 2011) and Britain (Gallie et al. 2004), Kim and Park (2006) and France (Givord and Maurin, 2004). While a number of these broad trends are brought together in Green (2006), the comparatively rare cross-national studies of change in job quality have relied primarily on the International Social Survey Programme (ISSP) surveys, which include periodic work orientation modules, and the European Working Conditions Surveys (EWCS). Using the former, Olsen et al. (2010) find evidence of convergence in job security and work intensity between four countries (Norway, West Germany, the US and Britain); while across a very wide range of countries, Green (2009) found that job insecurity approximately tracked the unemployment rate. Both these studies found that job quality was highest in the Nordic countries, but no higher in the other CMEs than in liberal market economies (Britain and Ireland), similar to Gallie (2003) who also finds with different data that jobs in Nordic countries afford relatively high levels of personal discretion.

The first three EWCS were drawn on by the OECD's analysis of "more and better jobs" (OECD, 2003) to show that work intensity was increasing across many European countries, while the trend in Good Physical Environment was mixed. These trends were confirmed by the $4^{\text {th }}$ EWCS in 2005, while a pattern of stable or slowly declining autonomy, and of convergence among the older member states was revealed (Eurofoundation, 2006; European Foundation, 2009). In none of these studies could the observed changes be termed radical, and in many cases rather little change is observed, similar to Handel's observation on the US data. None carry their analyses forward to the period following the onset of the great recession. ${ }^{7}$

Regarding trends in the dispersion of job quality, Kalleberg (2011) reports rising inequality in worker autonomy and workplace participation, but stability in the dispersion of intrinsic rewards over a quarter century interval in the US. No other study appears to have investigated how job quality dispersion has changed in other countries. Nor is it known whether traditional gaps in job quality between socio-economic groups are persisting, diminishing or even expanding, in the face of the heterogeneous trends outlined in the previous section. We ask, therefore, the following questions about trends in job quality in recent years:

- Has there been a substantive generally upward trend in the non-wage aspects of job quality, as suggested by an increasingly affluent economy and the post-Fordist perspective, or has there been a downward trend, more consistent with a neo-Fordist perspective? Alternatively, is the change characterized mainly by continuity in existing patterns?

- Has there been a trend towards greater inequality in the non-wage aspects of jobs?

- Is there a pattern of divergence or convergence between countries, in their average job quality levels and in the degrees of inequality; and are the changes consistent with institutional determinations implied by employment regime and production regime models?

- Are trends in inequality mirrored in changing gaps between the sexes, between young and older workers, across education levels, among occupations, and according to job contract status?

\footnotetext{
${ }^{7}$ Mention should also be made of another attempt to plot job quality trends (European Commission, 2008: Chapter 4), where a synthetic index is constructed primarily from elements in Labour Force Survey. While the latter has the advantage of providing annual data for all EC members, it lacks information on intrinsic job quality features and is therefore less informative.
} 


\section{The European Working Conditions Surveys}

To address these questions, we draw on successive waves of the European Working Conditions Survey. The $5^{\text {th }}$ and latest wave (EWCS5) comprises a sample of 44,000 people over 15 and in employment, drawn from 34 countries in 2010. This is a harmonized survey, comprising representative samples ranging from 1000 to 4000 per country. Earlier waves took place in 1991, 1995, 2000/01, 2005 and 2010. The surveys have evolved, both as new members joined the EU and as items were improved, added or subtracted in successive waves. It is possible to analyze trends in the distribution of job quality over time, but only for countries that have been members in multiple surveys, and using items that have been asked in identical ways in multiple waves. We therefore restrict our analyses to the $15 \mathrm{EU}$ countries that have subscribed since the 1995 wave. While very many items of continuous entry are available since then, refinements in 2005 facilitate extensions and modifications to the indices, and a small part of our analysis centers on the period $2005-2010 .^{8}$

\section{Constructing Indices of Job Quality}

In this section, we present how the indices of job quality were constructed from multiple response items available in the waves of 1995 onwards of the EWCS. We follow some general principles for index construction, as outlined for example in Muñoz de Bustillo et al., (2011b). After being normalized to the 0-1 range, the selected items were grouped into summative indices of four key aspects of job quality: Work Quality, Work Intensity (a negative indicator), Good Physical Environment and Working Time Quality. Some items have missing values, but in most cases these are few, which is a good indication of data quality. To avoid loss of information, when items are aggregated into indices we average over the items with non-missing values. Once constructed, each index was transformed to range from 0 to 100 .

The Work Quality index was constructed using items covering aspects of skills use or activities known from the literature to be proxies for skills use - specifically complexity, problem-solving, use of technology (computers), training and learning participation - and task discretion (with respect to the order methods and pace of tasks). None of these items on its own is ideal, but collectively they formed an index with an alpha statistic of 0.74 , suggesting that it may be just acceptable to regard them as capturing a single latent construct. The included eight items (each 0/1 dummy variables) are:

"Generally, does your main paid job involve:

a. solving unforeseen problems on your own,

b. complex tasks,

c. learning new things?

d. working with computers, PCs, network, or mainframe?"

Over the past 12 months, have you undergone any training paid for or provided by your employer or by yourself if self-employed?

"Are you able to choose or change:

a. your order of tasks,

b. your methods of work,

\footnotetext{
${ }^{8}$ An overview and more details can be found at http://www.eurofound.europa.eu/surveys/ewcs/index.htm.
} 


\section{c. your speed or rate of work?"}

The Work Intensity index was constructed using two items that capture features of a job that require intensive work, and five items capturing sources of work pressure. The items are conceived as heterogeneous manifestations of work intensity in various situations, rather than as variables reflecting an underlying single construct. The included items are:

"Does your job involve:

a- working at very high speed,

b- working to tight deadlines?"

Each item has a 7-point proportion-of-time scale, which was normalized to the 0/1 range; then the index was constructed as an average of these items and the normalized number of sources of work pressure, where the latter was obtained from the following items:

"On the whole, is your pace of work dependent, or not, on:

a- the work done by colleagues,

b- direct demands from people such as customers, passengers, pupils, patients etc.,

c- numerical production targets or performance targets,

d-automatic speed of a machine or movement of a product,

e- the direct control of your boss?"

These items are conceived as heterogeneous manifestations of work intensity in various situations, rather than as variables reflecting an underlying single construct present in all.

The Good Physical Environment index was constructed using items that capture exposure to environmental hazards and posture-related risks. For each item below there is a 7-point scale running from "never" to "all of the time", to which we ascribe values 0 to 6 :

"Please tell me, using the following scale, are you exposed at work to:

a- vibrations from hand tools, machinery,

b- noise so loud that you would have to raise your voice to talk to people,

c- high temperatures that make you perspire even when not working,

d- low temperatures whether indoors or outdoors,

e- breathing in smoke, fumes, powder or dust,

f- handling or being in skin contact with chemical products or substances?

Please tell me, using the same scale, does your main paid job involve:

a- tiring or painful positions,

b- carrying or moving heavy loads,

c- repetitive hand or arm movements?"

The index is constructed by averaging the responses across items, with the small number of missing values being recorded as 0 ("never"). One may hypothesize that there is an underlying construct in all workplaces capturing the absence of exposure to health risks: in support, the alpha statistic for the items in the index is 0.82 .

The Working Time Quality (WTQ) index aims to captures job features that affect work-life balance. The extent to which a person achieves work-life balance depends on personal 
circumstances, which, as noted in our introduction, are not included in the index. The focus is on the characteristics of the jobs and not those of the individual doing the job. Ideally, these would include facilities connected with the job, such as child care, but the most important aspects of the job that affect work-life balance involve working time - its extent, its conducive scheduling and flexibility. These, anyway, are the features that are consistently available in the survey. The items combined in the index available from 1995 are the following:

1- "How many hours do you usually work per week in your main paid job?"

2- "How many times a month do you work at night, for at least 2 hours between 10.00 pm and 05.00 am?"

3- "How many times a month do you work in the evening, for at least 2 hours between $6.00 \mathrm{pm}$ and $10.00 \mathrm{pm} ? "$

4- "How many times a month do you work on Saturdays?"

5- "How many times a month do you work on Sundays?"

In addition, an expanded variant for 2005 and 2010 of this index (WTQ_E) is available, including an item that captures the worker's discretion over working time arrangements, and a subsequent item capturing how much notice is given when those arrangements are changed by employers. We combine these derive a 5-point scale capturing these aspects of control over working time, identically as in de Bustillo et al., 2011a: 186). The exact items are:

"How are your working time arrangements set: a- they are set by the company, b- You can choose between several fixed working schedules determined by the company, cYou can adapt your working hours within certain limits, d- Your working hours are entirely determined by yourself?"

"Do changes in your work schedules occur regularly? (If YES) How long before are you informed about these changes?"

To what extent are these indices valid indicators of job quality? One aspect of their criterion validity is whether they are associated as expected with outcomes, and in this case we have suitable items within the survey capturing workers' perceptions of the impact of the job on their health and their work-life balance. We present this analysis in the appendix. ${ }^{9}$

\section{Findings}

Figure 1 gives the basic descriptives for each of the four indices available since 1995, together with a histogram of their distributions. Each index occupies more or less the whole range, while Good Physical Environment is bunched towards to the top end, reflecting the fact that only a minority of jobs have a preponderance of environmental or posture-related hazards. The indices are all 'lumpy', reflecting the fact that they are constructed from limited numbers of items each with categorical scales.

\{Figure 1 about here\}.

To gain an idea of the variation that lies behind these indices, one can compare some illustrative features of jobs where the indices are notably below or above their mean values. In the case of Work Quality, contrasting the set of jobs falling in the (inclusive) range 41-50 with those in the range 71-80, in the former set the proportions of jobs that involve solving problems, learning new things, and leeway to choose the methods of work are $83 \%, 50 \%$ and $65 \%$ respectively; while in the latter set the same proportions were $97 \%, 95 \%$ and $92 \%$.

\footnotetext{
${ }^{9}$ Further details about index construction can be found in Green and Mostafa (2012).
} 
In the case of Work Intensity one can compare the set of jobs in the 21-30 range with those in the 51-60 range. In the former set only 3\% of the jobs involve working at very high speed all or almost all of the time, and the workers are subject to an average of 1.5 sources of work pressure; this compares with $22 \%$ and 2.4 for the latter set with higher work intensity.

For Good Physical Environment, in jobs in the 65-74 range, $18 \%$ of jobs entail breathing in smoke, fumes, powder or dust at least half the time, and $51 \%$ involved tiring or painful positions at least half the time; while for the jobs in the 85-94 range the same proportions are $0.6 \%$ and $13 \%$.

Finally, for Working Time Quality, with jobs in the 45-54 range the average working week is 45 hours, and $32 \%$ of workers go to work on Sundays at least twice a month, compared with 36 hours and just $3 \%$ for jobs in the 75-84 range

\section{a) Overall Trends}

We begin our analysis of trends by presenting in Table 1a a description of changes in the means and in the dispersion of job quality, for all our non-wage job quality indices across all five waves of the survey, for all the older member states of the European Union (EU15) taken as a whole. The aim, in initially taking an aggregative approach, is to obtain an initial picture of the extent and overall direction of change, treating these countries as if they were a single labor market, something that is more a long-term objective of single-market policy rather than a realistic assumption about the present state of affairs. The risk of this approach, as we shall see, is that it may hide the considerable underlying heterogeneity in the sample, a problem that is common among analyses of Europe as a whole. The data have been weighted to take account of the differential size of the working population, as well as survey and nonresponse weights. For our measure of dispersion we use the Gini index.

\section{\{Table 1 about here $\}$.}

The first point to note from Table 1a is that job quality according to three of the indices is quite stable over time. To assess stability with a simple formal test, we regressed each index against time; Table 1a records with an asterisk whether there is a statistically significant trend at the $5 \%$ level. Since the full sample is quite large, even small changes are significant statistically, yet we are interested in substantive changes relative to the standard deviations of the indices (which range from 19 to 26, see Figure 1). We have therefore adopted a rule of thumb for identifying 'substantive' changes: whenever the mean value of an index changes significantly between 1995 and 2010 and by at least 3 points, Table 1a and subsequent tables show this by a direction-of-change arrow in the final column. Similarly, we use a directionof-change arrow to indicate a substantive rise or fall in inequality, when the Gini coefficient changes by at least 0.02 points. $^{10}$

With this convention, it can be seen that the mean level of Work Intensity index rose by 2.2 points, significantly but not amounting to a substantive change, while the mean values of Work Quality and Good Physical Environment were each stable. For these three indices the dispersion also changed very little, as indicated by the Gini coefficients.

By contrast there is a substantive rise of 5.4 points over time in the Working Time Quality index, accompanied by a fall by 0.025 points in the Gini coefficient. The rise in the mean is comprised of both declining work hours and falling use of shift work at weekends and night

\footnotetext{
${ }^{10}$ Across these countries, one might expect to find a Gini coefficient range of between 0.10 and 0.15 , depending on the index (see Tables 3 to 6). A Gini interval of 0.02 would be noticeable in terms of differences in percentile ratios.
} 
time. To illustrate with a specific example from one of the ingredients of this index: the proportion of workers in the EU15 countries who never worked on Saturdays rose from 44\% to $50 \%$ over the period. The simultaneous fall in the dispersion and rise in the mean partly reflects gains at the low end, with the index's $5^{\text {th }}$ percentile rising from 20.8 to 29.2 between 1995 and 2010; but it also picks up improvements for the large majority of workers: the median rose from 66.7 to 75.0 .

Since job quality varies across industries, it could be that some of the improvement is associated with industrial change. Within our sample period, service industries and public administration increased their share of employment from $65 \%$ to $73 \%$, while manufacturing and agriculture declined. Moreover, Working Time Quality is well below average in agriculture and well above in public administration. To see whether such compositional change was important we regressed Working Time Quality on year, and then on year and industry, with the result that the coefficient on year was reduced by only a small amount, from 0.35 (s.e. $=0.01$ ) to 0.32 (s.e. $=0.01$ ). We therefore conclude that the changes largely occurred within industry, rather than through industrial recomposition. ${ }^{11}$

Table 1a also shows the pattern of change between 2005 and 2010 in the expanded Working Time Quality (WTQ_E) index. There is no change over this short period, implying that the picture is not as optimistic as suggested by the more limited index that is available from 1995. The above trends in working time and weekend working are counterbalanced by an unfavorable change, over this short most recent period, in the extent to which employees can exercise choice over their working time.

Should these indices, which capture quite distinct concepts, be reduced and brought together in a single index of job quality? While some writers argue that a single index facilitates a stronger impact from job quality research, despite the extra assumptions that have to be made about the weights to be attached to each elements (e.g. European Commission, 2008; Muñoz de Bustillo et al., 2011a, 2011b ; Holman and McClellan, 2011), we have not been persuaded of the presentational advantages of a single index over those of a small number of separate indices whose names convey a reasonably direct relation to a known concept. Nor, as we shall see, could it be argued that a unified index would suffice because the indices are closely related or move in parallel. Table $1 \mathrm{~b}$ records the correlation coefficients between the four indices that are available from 1995 onwards. None of the coefficients are especially high, the largest in absolute terms being between Work Intensity and Good Physical Environment (0.38 in two of the waves). There can be seen no trend towards a closer linkage over time. These low correlations, and the fact that the indices are moving, if anything, in opposite directions, make a strong case for examining the indices separately, and not combining them into a single index of job quality.

\section{b) Job Quality Gaps}

The aggregate picture of stability and change in Europe's 15 can hide substantive differentiation between and within countries and groups. Moreover, since the statistics are weighted by population size the patterns of change in Table 1a can be dominated by a few large countries, failing to reveal evolutions taking place in the smaller countries. We next therefore examine how the indices differ between groups. Tables $2 \mathrm{a}$ to $2 \mathrm{~d}$ present the averages of the job quality indices by socio-economic groups. For this analysis we retained gender, age groups, education levels, type of employment contract and type of occupation.

\footnotetext{
${ }^{11}$ The same pattern is found for other trends reported below.
} 
\{Table 2a-2d about here\}.

Gender differences in aspects of job quality, not only in respect of wages, are especially relevant to an evaluation of progress towards gender equality (Smith et al., 2008). As can be seen, Work Quality is slightly higher for men, but the gap has been closing. The mean level of Work Quality rose by 0.58 points for females and dropped by 0.38 points for males. Meanwhile Work Quality for older individuals (above the age of 40) increased by 1.18 points while it dropped by 1.27 points for individuals younger than 40 . When it comes to education, the findings suggested that Work Quality dropped by 2.88 points for those who have finished their education at the age of 15 , it dropped by 2.31 points for those who finished their education between the age of 16 and 19, and finally it remained almost the same for the those who finished their education at an older age than 20. Work Quality is slightly increasing for all types of employment contracts. The biggest increase in Work Quality is for those with a temporary employment agency contract. However, one should keep in mind that the sudden jump between 2005 and 2010 may be related to the economic recession. In other words, more of those with temporary employment agency contract lost their jobs raising the average quality of the remaining jobs. Looking across occupations, Work Quality increased for professionals by 3.4 points over this period of time while it decreased by 8.8 points for service workers. It is also worth noting that professional workers started at a high average of 74.5 points in 1995 while service workers started at an average of 59.2 in 1995 and ended at 50.4 in 2010 - so the gap widened between these groups.

In contrast to earlier findings for Britain and the United States (Gorman and Kmec, 2007), across the EU15 work intensity is greater for males than for females, and there is no indication of this gap closing. On the contrary, the Work Intensity index for males increased by 2.6 points over the 1995-2005 period, while that of females increased by 1.9 points. Work is also intensifying faster for individuals younger than 40 and for individuals with the highest level of education.

While work was intensifying for all employment contract types, there was a striking and large increase after 2000 for those with a temporary employment agency contract. ${ }^{12}$ Among occupations work was intensifying for professionals, technicians and associate professionals, craft workers, and plant and machine operators, but there was volatility among agricultural workers and little change among service workers.

Good Physical Environment was about 8 points higher for females than for males. It was also greater for those with more education and in higher status occupational groups. These gaps remained stable over time, as did those between age groups, employment contract type, and occupational groups. The only exception was craft workers where Good Physical Environment dropped by 4.2 points.

Working Time Quality has increased for both genders with males having a lower value than females in all periods. One should also note that males and females are slightly converging on this index. Working Time Quality has also increased for both age groups over the (19952005) period and the gap between the two is shrinking. When it comes to education, the highest increase - of 6.3 points - is for the lowest educational group. These small diminutions in the Working Time Quality gaps are in the same direction as the overall decline in inequality of this index reported in the previous section.

While Working Time Quality has gone up for all types of employment contracts with the highest increase for apprentices (5 points).

\footnotetext{
${ }^{12}$ It should be noted, in this context, that the European directive for agency workers was not agreed until 2008 , and would not have taken effect in time to bring out any convergence with the conditions of other workers.
} 
Working Time Quality also went up for all occupational groups but the variation ranged between 1.8 points for professionals and 10 points for skilled agricultural and fishery workers. One should note that skilled agricultural workers and craft workers started at a relatively low level, professional workers from a high level, indicating some convergence.

\section{c) Job Quality Distributions Between and Within Countries}

The above analysis of Table 2 has shown that aggregate stability can hide heterogeneous patterns of change among different groups of workers. However, to examine whether the changes are consonant with "universal" theories that emphasize common causes, or with differentiated theories that allow for national labor market institutions and policies to generate divergent patterns, with Table 3 and Figures 2 and 3 we now investigate the picture for each index across the international dimension and across time. We study countries separately, though in the light of what has been said about the differences between regimes. This method has the advantages of not pre-judging whether countries fit with particular institutional categorizations, and of allowing us to include many countries that do not neatly fit the regimes literature.

\section{\{Table 3a-3d about here .}

As a baseline we look briefly first at the intercountry differences in job quality in 1995. In respect of three of the indices one can detect a clear general association between job quality and a country's affluence. Work Quality is low for Greece (48.2) and for Portugal (53.5), while it is high for the Netherlands (70.0) and for Finland (70.1). Similarly, with Good Physical Environment and Working Time Quality, less affluent countries are to be found at the lower end of the range. With Work Intensity, however, the relationship with affluence is far from clear, given that some of the richer countries have a high score (Germany), and some a very low score (Belgium). To formally confirm these impressions we regressed each index on the 1995 GDP per capita (in units of a thousand US dollars), with the following estimated coefficients: for Work Quality, 1.3 ( $\mathrm{p}=0.03)$; for Good Physical Environment, $1.0(\mathrm{p}=0.00)$; for Working Time Quality, $1.3(\mathrm{p}=0.01)$; but for Work Intensity, $0.4(\mathrm{p}=0.41)$, indicating no significant relationship. ${ }^{13}$ It thus appears that affluence 'buys' the workers in a country a higher job quality in some but not all dimensions, though the process of causation might also be in the opposite direction.

Variations in job quality across countries only partially conform to those proposed in the literature. From Table $3 \mathrm{a}$ it is confirmed, as previous studies have found looking at task discretion (e.g. Gallie, 1993), that the social corporatist countries are highly ranked, with jobs in Denmark having the highest-ranked work quality (an index of 73.4). Many of the CMEs are highly ranked in terms of average Working Time Quality (Table 3d), the Netherlands having the highest score on this index. However, in terms of the other indices (Tables $3 \mathrm{~b}$ and 3c), the CMEs do not stand out as having better job quality. For example, the UK is among the top for Good Physical Environment (Table 3c), while the CMEs range from high (Denmark) to low (France, Austria). It can also be seen from Table 3a that Work Quality in the CMEs with dualist regimes varies quite a lot, and does not stand out as being collectively better than in the UK. Overall, the variation among countries appears to vindicate our preference for presenting the data for countries separately, except for one generalization: that the social corporatist countries are ranked among the lowest for dispersion of job quality, in respect of all four indices. Looking at the Gini coefficients shown throughout Table 3,

\footnotetext{
${ }^{13}$ For the purposes of examining this association, we omitted Luxemborg, an outlier with an especially high per capita GDP, since a high proportion of Luxemborg workers commute from other countries.
} 
Sweden, Finland and Denmark indicate low inequality in each of these four dimensions of job quality.

\{Figures 2 and 3 about here\}.

With this baseline we now consider the trend patterns for each dimension over 1995 to 2010, illustrated in . Table 3a and Figure 2 shows that, the average level of Work Quality increased substantively in 8 countries. These are: Austria, Belgium, Denmark, Finland, Greece, Ireland, Luxembourg, and Spain. The highest increase is in Luxembourg. This picture of change differs from the aggregate narrative of stability reported in Table 1, and the contrast is attributable to the fact that in the three large countries which dominate the overall sample France, Germany and the UK - change was largely absent.

Despite these changes for the mean values there is little evidence of national divergence. Work Quality is high in the social corporatist countries both in 1995 and in 2010.The range between the highest and lowest-ranking countries (Finland and Greece) came down a small amount, from 22 to 20 points. We conducted a simple formal test for convergence by regressing the change in the country-level mean against the initial mean value: evidence of a significant negative (positive) coefficient on the initial mean would signify convergence (divergence). The coefficient, though negative, was insignificant $(\mathrm{p}=0.103)$.

In contrast to the level, the dispersion of Work Quality, measured by the Gini coefficients, was relatively stable in the large majority of countries (Figure 3). The only countries where inequalities increased by more than 2 points were France, Spain and the UK. By 2010 Spain had become the most unequal, while the Nordic countries remained by far the least unequal.

Turning to Work Intensity (Table 3b), most countries in the EU15 experienced a progressive intensification of work over the $(1995$ - 2010) period, while inequalities on this index decreased in the same time. These countries are: Belgium, France, Germany, Greece, Ireland, Italy, Luxembourg, Spain, and Sweden. There are, however, three contrasting countries. In Austria and Portugal work intensity has been volatile, and while it arrived at a low note in 2010 it was high in 2005. In the UK Work Intensity was at an exceptionally high level in 1995, and subsequently declined somewhat; however, it turns out that the early 1990s was, according to both the EWCS and other sources, a period of very substantive intensification. Comparing either the late 1990s or the 2000s with the start of the 1990s, work effort in the UK rose according to multiple sources (Green, 2006).

Both the means and the dispersion of Work Intensity converged between countries over the period. For example, the coefficient of variation of the means across countries fell from 0.63 to 0.61 , and the above-mentioned formal test confirms that a lower initial level is associated with a greater increase $(p=0.01)$. The coefficient of variation across countries of the Gini indices fell a small amount from 0.11 to 0.10 . Even so, the dispersion remained lowest in the Nordic countries.

The results are mixed for Good Physical Environment (Table 3c). The average levels rose in three countries (Greece, Netherlands, and the UK) and dropped in two others (Belgium, and Luxembourg). On the other hand, the Gini coefficient dropped by more than two points in Netherlands, Portugal, Spain, and the UK. Thus the major pattern consists of a limited change in average Good Physical Environment and a somewhat more generalized drop in the inequality. There is evidence of convergence of the mean levels, and indeed the largest rises were in Greece and the UK both of which had below average Good Physical Environment in

\footnotetext{
${ }^{14}$ The fall away of the UK from being one of the highest on the Work Quality index in 1995 reflects a decline in task discretion that has also been found from data in the UK Skills Surveys (Gallie et al., 2004).
} 
1995. Yet, there is some divergence in the inequality, with the coefficient of variation across countries of the Gini index rising from 0.19 to 0.23 .

Working Time Quality (Table 3d) increased in 11 countries, namely: Austria, Belgium, Finland, France, Ireland, Italy, Luxembourg, Netherlands, Portugal, Spain and the UK. The highest increase was about 11 points in France. One should also note that average Working Time Quality did not decrease in any of the 15 countries. On the other hand, the dispersion of Working Time Quality decreased in 9 countries: Austria, Belgium, Finland, France, Ireland, Italy, Portugal, Spain, and the UK; and rose only in Sweden. The Nordic countries remain among the most equal, joined in respect of this index by France. At the other end of the spectrum, workplaces in Greece stand out as having both the lowest and most unequal Working Time Quality. Yet over time, both the means and the Gini indices converged between countries. In short, underpinning the overall change reported in Table 1, in most countries separately there was a clear trend consisting of an enhancement in Working Time Quality combined with an equalization process within, and convergence between, countries.

\section{Discussion: Continuity and Change in Patterns of Job Quality}

We have presented a picture of how several dimensions of non-wage job quality vary between groups and countries, and how they have changed over a recent 15 -year period. In addition to examining together 15 countries, we have for the first time placed an emphasis not only on the levels of job quality indices but also on their dispersion across groups and countries. The literature led us to look for differences among countries according to both their level of affluence and their institutional regimes, and for certain trends over time, which might be consistent with either optimistic or pessimistic perspectives, and which could conceivably be either universal or differentiated among countries. While it is beyond the scope of this paper to test specific explanations for the changes reported, it is of interest to review to what extent the pattern of change is consistent with the tenor of the theories of change outlined in Section 2.

Our baseline analysis confirmed that, as expected, the average levels of job quality tended to be higher in the more affluent countries. While we have not attempted to gather countries in groups pre-defined by employment or production regimes, the results also confirmed some predictions about the differences between countries associated with their institutional structures. The countries typically seen as Coordinated Market Economies show high levels of Working Time Quality, and of these, the subset of social corporatist countries have high levels of Work Quality. This superiority in Work Quality has been attributed to a long history of trade union concern with issues of job design in the social corporatist countries, and a rather more equal balance of power than elsewhere. Yet there was no support for the view that countries with Coordinated Market Economies had systematically higher job quality in the other respects examined here. Where the social corporatist countries are systematically different is that they have especially low dispersions of job quality according to all indices, and this is consistent with their well-known low levels of income inequality attributable to the tradition of centralized solidarity bargaining.

As for the trends, taking as a whole all the 15 European countries that formed the European Union in 1995, the levels and distributions of the job quality indices across individuals and groups remained relatively stable over the period. Underneath the current of change we have been describing there is a strong pool of continuity in both the level and the inequality of job quality in these countries. There is no evidence of radical disjuncture in job quality, even taking into account the time span of the Great Recession. Nevertheless, there was a steady 
rise in the Working Time Quality index. While the trend might need qualifying, once further features associated with flexibility are included, this rise appears consistent with universal optimistic theories about the changing nature of work, including the idea that work features do respond positively if slowly to changing needs as in the case of work-life balance.

To some extent, however, the relative stability reflects the size dominance of France, Germany and the UK. When countries are considered separately a somewhat different pattern is found. Several countries experienced rises in the Work Quality index, though arguably these rises are surprisingly slow, given that the Great Recession might have been expected to selectively diminish the share of low quality jobs in this dimension. Meanwhile, the widespread rise in work intensity can also be seen as reflecting universal trends in technology and/or work organization, and the pressures of global competition; but in this dimension the implications for job quality are negative.

With regard to Good Physical Environment, the high degree of continuity is not consistent with the optimistic view that there should be general increases in job quality. Nevertheless this is an index that starts from a fairly high level, and for which improvements rely as much on the gradual spread of health and safety awareness as on the changing industrial structure. For certain hazards it is probably necessary to look for focused advances: a notable achievement, for example, of the recent 5-year period is the decline from $77.1 \%$ to $64.1 \%$ in the percent of employed people exposed to tobacco smoke at work. ${ }^{15}$

The trends in inequality that we have reported have also been fairly widespread, even if not universal. The falls in the dispersion of Good Physical Environment can be seen as reflecting the spread of national and supranational regulation. Similarly, the fall in the inequality of Working Time Quality, partly reflected also in slowly declining gaps between high and low education groups, could be interpreted as responding to a generalized demand that grew with the ubiquitous rising trend for female participation in the labor force. The observed widespread reductions in the dispersion of Work Intensity are consistent with the impact of technology being greatest among those whose required effort was below average, as implied in the theory of effort-biased technological change. If there was no change in the association between intensive work effort and pay (about which we have no evidence) a reduction in the dispersion of work intensity would also amount to a fall in overall inequality. ${ }^{16}$ These falls in inequality stand in contrast to previously-noted rises in wage inequality. An account of why in several countries one observes opposing trends for wages and other aspects of job quality should be the focus of future research.

While all these patterns of change are seen in many countries, they are unsurprisingly not found in all. The question arises, then, as to whether different countries' trends show divergence, this being a possible indicator of the power of heterogeneous country-level institutions to take job quality on different paths. We have found this not to be the case. Indeed, there has been a pattern of slow national convergence in the means and dispersion of Working Time Quality and of Work Intensity, and in the means of Good Physical Environment. Only for the Gini indices of Good Physical Environment is there some evidence of minor divergence, and otherwise there was little change in the spread across countries. This pattern does not necessarily imply that generalized forces of technology and global competition are behind the changes. Within Europe regulation patterns can become

\footnotetext{
${ }^{15}$ Evidence about tobacco smoke exposure is only available since 2005.

16 The extent of this possible reduction depends on how the different indices are valued (upon which matter there are differences of approach that are not addressed here). Moreover, should the association between effort and wages be reduced, the effect on overall inequality is ambiguous, no matter how effort is weighted against pay.
} 
generalized through policy learning, copying, and the open method of coordination, and through Brussels' directives that are subsequently enacted by national governments; and it is plausible to expect regulation to have an equalizing effect on job quality.

Finally, we have also found mostly stable gaps in job quality between men and women and between socio-economic groups, which are in most cases unsurprising. The stability is a reflection of the slow-changing inequality across the whole sample of countries. ${ }^{17}$ Nevertheless we have identified certain striking shifts that have implications for further analysis, including the dramatic rise in work intensity of temporary agency workers, and the decline in work quality among service workers.

The indices presented in this paper are far from perfect tools for understanding the changing workplace, even if they represent an advance on previous quantitative descriptions. Notably, the items on skills requirements of jobs (constituents of the Work Quality index) need development. Until recently the EWCS has not generated data on social support within the workplace, so we cannot look at long-term trends. And it is only recently that the survey has been extended to encompass as many as 34 countries. A broader spread of trends will be revealed in time, as long as continuity is maintained. Meanwhile, the surveys hitherto are all cross-sections of data, rather than longitudinal, thereby limiting the extent to which they can contribute to identifying causal processes.

\footnotetext{
${ }^{17}$ Sample sizes militate against a country-level gap analysis; however job quality gaps within country-groups could be amenable to analysis in future work.
} 
Appendix Job Quality and Subjective Well-Being

Table A1 Determinants of Subjective Well-being At Work

\begin{tabular}{lccc}
\hline & $\begin{array}{c}\text { a-Health Problems } \\
\text { Caused by Work }\end{array}$ & $\begin{array}{c}\text { b-Health and } \\
\text { Safety Risk }\end{array}$ & $\begin{array}{c}\text { c-Subjective } \\
\text { Wellbeing }\end{array}$ \\
\hline Work Quality & 0.00324 & 0.00161 & \\
& $(0.000)$ & $(0.025)$ & \\
Work Intensity & -0.00816 & 0.00966 & \\
& $(0.000)$ & $(0.000)$ & \\
Good Physical Environment & 0.0282 & -0.0472 & \\
& $(0.000)$ & $(0.000)$ & \\
Working Time Quality & 0.00708 & -0.0132 & 0.0334 \\
& $(0.000)$ & $(0.000)$ & $(0.000)$ \\
Male & 0.118 & -0.106 & 0.00957 \\
& $(0.000)$ & $(0.005)$ & $(0.719)$ \\
Age & & & -0.05 \\
& -0.0672 & 0.0618 & $(0.000)$ \\
Age^2 & $(0.000)$ & $(0.000)$ & \\
& & & 0.00071 \\
\hline Number of dependents & 0.000723 & -0.0006 & $(0.000)$ \\
& $(0.000)$ & $(0.000)$ & -0.0533 \\
& & & $(0.000)$ \\
\hline
\end{tabular}

a. The variable capturing the subjective effect of work on health takes three values: 0 if the effect is negative, 1 if there is no effect and 2 if the effect is positive. Estimation by ordinal logit.

b. "Health and safety risk at work" takes the value of 0 if the work does not perceive any risk caused by his work and 1 otherwise. Estimation by logit.

The variable capturing subjective work life balance takes four values on a four points scale.

c. Hours Fit: "In general, do your working hours fit in with your family or social commitments outside work very well, well, not very well or not at all well?". Scale from 0 ("not at all well") to 3 ("very well"). Estimation by ordinal logit.

Table A1 presents simple tests of the criterion validity of the four job quality indices available from 1995, used in the paper. It is argued that there is expected to be a correlation between subjective well-being and the satisfaction of need, and that job quality indices are designed to capture aspects of need satisfaction from work. Hence, we do expect an appropriate relation between each index and subjective well-being; and this expectation provides a test of criterion validity. We apply this test using the 2010 data.

Controlling for sex, age and age squared, the first column looks at an indicator of positive well-being, the worker's self-perceived effect of the job on his/her health. This is positively 
related to Work Quality, Good Physical Environment and Working Time Quality, and negatively related to Work Intensity, as expected. Not surprisingly, given the nature of this outcome variable, the index that has the largest estimated association with the outcome is Good Physical Environment. The second column provides further equivalent validation, but with a negative indicator, health and safety risk. The signs are reversed, with the exception that Work Quality is positively related to the perception of health and safety risk. The third column focuses on work-life balance. The survey contains an item capturing the worker's assessment of how well his/her work hours fit family or social commitments outside work. This assessment is expected to be positively related to the Working Time Quality index. As a control to capture outside commitments, we include the number of dependent children below 16 in the household. Again, the index performs as expected.

All these coefficients are not presented as unbiased estimates of causal impacts of the indices on well-being, since other variables could be affecting both the dependent and independent variables. There could, for example, be a common rater bias. Hence this is only a weak test of validity. However, the maintained assumption is that these biases are either downward or if upward are not of such great magnitude as to reverse the sign of a coefficient.

\section{References.}

Atkinson, A.B. (2009), The Changing Distribution of Earnings in OECD Countries, Oxford University Press.

Autor, D. H., F. Levy and R. J. Murnane (2003). "The skill content of recent technological change: An empirical exploration." Quarterly Journal of Economics 118(4): 1279-1333.

Bescond, D., A. Chataignier and F. Mehran (2003). "Seven indicators to measure decent work: An international comparison." International Labour Review 142 (2): 179-211.

Danford, A., M. Richardson, P. Stewart, S. Tailby and M. Upchurch (2008). "Partnership, high performance work systems and quality of working life." New Technology Work and Employment 23(3): 151-166.

Estevez-Abe, G. (2005). "Gender bias in skills and social policies: the varieties of capitalism perspective on sex segregation." Social Politics 12(2): 180-215.

Eurofound (2006), Fifteen years of working conditions in the EU: charting the trends, Dublin: Eurofound.

European Commission (2008). Employment in Europe 2008, European Commission, Directorate-General for Employment and Social Affairs.

European Foundation for the Improvement of Living and Working Conditions (2002). Quality of work and employment in Europe: issues and challenges. Luxembourg, Foundation Paper N.1, February 2002.

European Foundation for the Improvement of Living and Working Conditions (2009). Convergence and divergence of working conditions in Europe: 1990-2005. Luxembourg, Office for Official Publications of the European Communities,.

Felstead, A., D. Gallie, F. Green and Y. Zhou (2010). "Employee Involvement, the Quality of Training and the Learning Environment: An Individual-Level Analysis." International Journal of Human Resource Management 21(10): 1667-1688.

Fevre, R. (2007). "Employment insecurity and social theory: the power of nightmares." Work Employment and Society 21: 517-535. 
Gallie, D. (2003). "The Quality of Working Life: Is Scandinavia Different?" European Sociological Review 19(1): 61-79.

Gallie, D. (2007a). "Production regimes and the quality of employment in Europe." Annual Review of Sociology 33: 85-104.

Gallie, D. (2007b). Production Regimes, Employment Regimes, and the Quality of Work. Employment Regimes and the Quality of Work. D. Gallie. Oxford, Oxford University Press: $1-34$.

Gallie, D., A. Felstead and F. Green (2004). "Changing patterns of task discretion in Britain." Work Employment and Society 18(2): 243-266.

Ghai, D. (2003). "Decent work: concept and indicators." International Labour Review 142 (2): 113-145.

Givord, P. and E. Maurin (2004). "Changes in job security and their causes: An empirical analysis for France, 1982-2002." European Economic Review 48(3): 595-615.

Goos, M. and A. Manning (2007). "Lousy and lovely jobs: The rising polarization of work in Britain." Review of Economics and Statistics 89(1): 118-133.

Goos, M., A. Manning and A. Salomons (2010). Explaining Job Polarization in Europe: The Roles of Technology, Globalization and Institutions, London School of Economics, CEP Discussion Paper No 1026.

Gorman, E. H. and J. A. Kmec (2007). "We (Have To) Try Harder. Gender and Required Work Effort in Britain and the United States." Gender \& Society 21(6): 828-856.

Green, F. (2004). "Why has work effort become more intense?" Industrial Relations 43(4): 709-741.

Green, F. (2006). Demanding Work. The Paradox of Job Quality in the Affluent Economy. Woodstock, Princeton University Press.

Green, F. (2009). "Subjective Employment Insecurity Around The World." Cambridge Journal of Regions, Economy and Society 2(3): 343-363.

Green, F. and T. Mostafa (2012). Trends in job quality in Europe: A report based on the fifth European Working Conditions Survey. Dublin: Eurofound.

Hall, P. and D. Soskice (2001). An Introduction to Varieties of Capitalism. Varieties of Capitalism. P. Hall and D. Soskice. Oxford, Oxford University Press: 1-70.

Handel, M. J. (2005). "Trends in perceived job quality, 1989 to 1998." Work and Occupations 32(1): 66-94.

Holman, D. and C. McClellan (2011). Job Quality in Growing and Declining Economic Sectors of the EU, University of Manchester, walqing working paper 2011.3.

Kalleberg, A. L. (2011). Good Jobs, Bad Jobs. New York, Russell Sage Foundation.

Kim, A. E. and I. Park (2006). "Changing trends of work in South Korea - The rapid growth of underemployment and job insecurity." Asian Survey 46 (3): 437-456.

Körner, T., K. Puch and C. Wingerter (2011) "Quality of employment. Earning money and what else counts." Wiesbaden, Statistisches Bundesamt (Federal Statistical Office).

Lehto, A.-M. and H. Sutela (2005). Threats and Opportunities. Findings of Finnish Quality of work Life Surveys 1977-2003. Helsinki, Statistics Finland. 
Muñoz de Bustillo, R., E. Fernández-Macías, J.-I. Antón and F. Esteve (2011a). "E pluribus unum? A critical survey of job quality indicators." Socio-Economic Review 9: 447-475.

Muñoz de Bustillo, R., E. Fernández-Macías, J.-I. Antón and F. Esteve (2011b). Measuring More than Money:The Social Economics of Job Quality. Cheltenham, Edward Elgar.

OECD (2008). Growing Unequal? Income Distribution and Poverty in OECD Countries. Paris, OECD.

Osterman, P. (2000). "Work reorganization in an era of restructuring: Trends in diffusion and effects on employee welfare." Industrial \& Labor Relations Review 53(2): 179-196.

Olsen, K. M., A. L. Kalleberg and T. Nesheim (2010). "Perceived job quality in the United States, Great Britain, Norway and West Germany, 1989-2005." European Journal of Industrial Relations 16(3): 221-240.

Peña-Casas, R. (2009). More and Better Jobs: Conceptual Framework and Monitoring Indicators of Quality of Work and Employment in the EU Policy Arena. Edinburgh, Working Papers on the Reconciliation of Work and Welfare in Europe, REC-WP 06/2009.

Rubery, J. and D. Grimshaw (2001). "ICTs and employment: The problem of job quality." International Labour Review 140(2): 165-192.

Schmidt, J. (2001). Did Job Quality Deteriorate in the 1980s and 1990s? Sourcebook of Labor Markets: Evolving Structures and Processes. I. Berg and A. L. Kalleberg. New York, Kluwer Academic: 387-407.

Smith, M., B. Burchell, C. Fagan and C. O'Brien (2008). "Job quality in Europe." Industrial Relations Journal 396 (586-603).

Stiglitz J., Sen, A. and Fitoussi, J.P., (2009) Report by the Commission on the Measurement of Economic Performance and Social Progress, downloadable at www.stiglitz-sen-fitoussi.fr.

Thelen, K. (2004). How Institutions Evolve. The Political Economy of Skills in Germany, Britain, The United States, and Japan. Cambridge, Cambridge University Press. 
Table 1a. The Distribution of Job Quality Indices in EU15 Countries, 1995-2010.

\begin{tabular}{lccccccc}
\hline Indices & & 1995 & 2000 & 2005 & 2010 & Change & Sig \\
\hline Work Quality & Mean & 61.2 & 59.4 & 59.5 & 61.2 & & $*$ \\
Work Intensity & Mean & 40.1 & 40.8 & 43.4 & 42.3 & & $*$ \\
Good Physical Environment & Mean & 78.7 & 78.5 & 78.9 & 79.2 & & $*$ \\
Working Time Quality & Mean & 62.6 & 65.2 & 66.8 & 68.0 & $\uparrow$ & $*$ \\
Working Time Quality (Expanded) & Mean & na. & na. & 59.5 & 59.3 & & \\
& & & & & & \\
Work Quality & Gini & 0.208 & 0.219 & 0.209 & 0.217 & \\
Work Intensity & Gini & 0.334 & 0.32 & 0.31 & 0.319 & \\
Good Physical Environment & Gini & 0.130 & 0.131 & 0.126 & 0.120 & \\
Working Time Quality & Gini & 0.184 & 0.171 & 0.165 & 0.159 & $\downarrow$ \\
Working Time Quality (Expanded) & Gini & na. & na. & 0.153 & 0.152 & & \\
\hline indicas that the traf & is &
\end{tabular}

* indicates that the trend of the means is statistically significant at the 5\% level. A directional arrow records that the change is "substantive", that is, at least 3 points in the average level, and for the Gini index at least 0.02 .

Table 1b. The correlation coefficients between the four indices.

\begin{tabular}{clccc}
\hline Year & \multicolumn{1}{c}{ Index } & $\begin{array}{c}\text { Work } \\
\text { Quality }\end{array}$ & $\begin{array}{c}\text { Work } \\
\text { Intensity }\end{array}$ & $\begin{array}{c}\text { Good } \\
\text { Physical } \\
\text { Environment }\end{array}$ \\
\hline \multirow{2}{*}{1995} & $\begin{array}{l}\text { Work Intensity } \\
\text { Good Physical } \\
\text { Environment }\end{array}$ & 0.046 & 1.000 & \\
& Working Time Quality & -0.014 & -0.113 & 0.140 \\
\hline \multirow{2}{*}{2000} & Work Intensity & 0.037 & 1.000 & \\
& Good Physical & & & \\
& Environment & 0.196 & -0.379 & 1.000 \\
& Working Time Quality & -0.045 & -0.099 & 0.140 \\
\hline \multirow{2}{*}{2005} & Work Intensity & 0.011 & 1.000 & \\
& Good Physical & & & 1.000 \\
& Environment & 0.228 & -0.378 & 0.145 \\
\hline \multirow{2}{*}{ Working Time Quality } & Work Intensity & -0.037 & -0.164 & \\
& Good Physical & 0.035 & 1.000 & 1.000 \\
& Environment & & & 0.123 \\
\hline
\end{tabular}


Table 2a. Work Quality Gaps by Gender, Age, Contract Type, and Occupational Group.

\begin{tabular}{|c|c|c|c|c|c|c|}
\hline $\begin{array}{l}\text { Socio- } \\
\text { economic } \\
\text { groups }\end{array}$ & Categories & 1995 & 2000 & 2005 & 2010 & Change \\
\hline \multirow{2}{*}{ Gender } & Female & 59.6 & 58.4 & 58.8 & 60.2 & \\
\hline & Male & 62.4 & 60.2 & 60.1 & 62.0 & \\
\hline \multirow{2}{*}{ Age } & Younger than 40 & 61.3 & 59.2 & 58.6 & 60.0 & \\
\hline & Older than 40 & 61.1 & 59.7 & 60.5 & 62.3 & \\
\hline \multirow{3}{*}{$\begin{array}{l}\text { Education } \\
\text { levels }\end{array}$} & Finished education at the age of 15 & 50.6 & na. & 48.5 & 47.7 & \\
\hline & Finished education between the age of 16 to 19 & 60.7 & na. & 56.6 & 58.4 & \\
\hline & Finished education at an older age than 20 & 70.2 & na. & 70.1 & 70.5 & \\
\hline \multirow{5}{*}{$\begin{array}{l}\text { Type of } \\
\text { contract }\end{array}$} & An indefinite contract & 62.2 & 60.1 & 61.0 & 62.5 & \multirow{4}{*}{$\uparrow$} \\
\hline & A fixed term contract & 53.4 & 53.8 & 53.4 & 53.2 & \\
\hline & A temporary employment agency contract & 44.2 & 42.7 & 43.9 & 49.5 & \\
\hline & An apprenticeship or other training scheme & 52.6 & 52.7 & 58.5 & 53.9 & \\
\hline & Other & 53.3 & 50.4 & 46.3 & 47.7 & $\downarrow$ \\
\hline \multirow{9}{*}{ Occupation } & Legislators, senior officials and managers & 73.5 & 72.0 & 71.4 & 75.4 & \multirow{3}{*}{$\uparrow$} \\
\hline & Professionals & 74.5 & 74.9 & 75.0 & 77.9 & \\
\hline & Technicians and associate professionals & 69.7 & 69.8 & 69.8 & 71.5 & \\
\hline & Clerks & 66.1 & 64.9 & 63.1 & 62.2 & $\downarrow$ \\
\hline & $\begin{array}{l}\text { Service workers and shop and market sales } \\
\text { workers }\end{array}$ & 59.2 & 50.1 & 52.6 & 50.4 & \multirow{5}{*}{$\downarrow$} \\
\hline & Skilled agricultural and fishery workers & 52.3 & 54.7 & 58.9 & 54.2 & \\
\hline & Craft and related trades workers & 55.7 & 55.2 & 52.5 & 55.6 & \\
\hline & Plant and machine operators and assemblers & 44.0 & 42.3 & 37.9 & 43.8 & \\
\hline & Elementary occupations & 43.8 & 39.2 & 42.8 & 41.4 & \\
\hline
\end{tabular}

Directional arrows record that the trend is statistically significant at the 5\% level, and that the change is "substantive", that is, at least 3 points. 
Table 2b. Work Intensity Gaps by Gender, Age, Contract Type, and Occupational Group.

\begin{tabular}{|c|c|c|c|c|c|c|}
\hline $\begin{array}{l}\text { Socio- } \\
\text { economic } \\
\text { groups }\end{array}$ & Categories & 1995 & 2000 & 2005 & 2010 & Change \\
\hline \multirow{2}{*}{ Gender } & Female & 37.3 & 38.0 & 39.7 & 39.2 & \\
\hline & Male & 42.2 & 42.8 & 46.2 & 44.8 & \\
\hline \multirow{2}{*}{ Age } & Younger than 40 & 41.5 & 42.8 & 45.5 & 44.2 & \\
\hline & Older than 40 & 38.4 & 38.3 & 41.2 & 40.4 & \\
\hline \multirow{3}{*}{$\begin{array}{l}\text { Education } \\
\text { levels }\end{array}$} & Finished education at the age of 15 & 39.0 & na. & 41.3 & 38.3 & \\
\hline & Finished education between the age of 16 to 19 & 41.8 & na. & 45.0 & 43.7 & \\
\hline & Finished education at an older age than 20 & 38.3 & na. & 42.0 & 42.0 & $\uparrow$ \\
\hline \multirow{5}{*}{$\begin{array}{l}\text { Type of } \\
\text { contract }\end{array}$} & An indefinite contract & 41.5 & 42.0 & 44.3 & 43.8 & \\
\hline & A fixed term contract & 40.2 & 40.8 & 45.0 & 43.9 & $\uparrow$ \\
\hline & A temporary employment agency contract & 40.5 & 40.9 & 52.6 & 53.0 & $\uparrow$ \\
\hline & An apprenticeship or other training scheme & 39.8 & 43.9 & 48.7 & 44.5 & $\uparrow$ \\
\hline & Other & 34.3 & 40.2 & 40.8 & 38.1 & $\uparrow$ \\
\hline \multirow{9}{*}{ Occupation } & Legislators, senior officials and managers & 42.4 & 41.1 & 43.2 & 45.0 & \\
\hline & Professionals & 36.5 & 37.2 & 39.8 & 40.1 & $\uparrow$ \\
\hline & Technicians and associate professionals & 36.8 & 39.8 & 41.9 & 40.2 & $\uparrow$ \\
\hline & Clerks & 40.3 & 39.2 & 42.7 & 42.1 & \\
\hline & $\begin{array}{l}\text { Service workers and shop and market sales } \\
\text { workers }\end{array}$ & 36.3 & 35.7 & 39.9 & 37.7 & \\
\hline & Skilled agricultural and fishery workers & 36.8 & 37.5 & 42.3 & 34.2 & \\
\hline & Craft and related trades workers & 45.5 & 47.5 & 52.4 & 49.2 & $\uparrow$ \\
\hline & Plant and machine operators and assemblers & 48.6 & 50.1 & 53.0 & 52.0 & $\uparrow$ \\
\hline & Elementary occupations & 37.0 & 38.6 & 38.5 & 40.2 & $\uparrow$ \\
\hline
\end{tabular}

Directional arrows record that the trend is statistically significant at the 5\% level, and that the change is "substantive", that is, at least 3 points. 
Table 2c. Good Physical Environment Gaps by Gender, Age, Contract Type, and Occupational Group.

\begin{tabular}{|c|c|c|c|c|c|c|}
\hline $\begin{array}{l}\text { Socio- } \\
\text { economic } \\
\text { groups }\end{array}$ & Categories & 1995 & 2000 & 2005 & 2010 & Change \\
\hline \multirow{2}{*}{ Gender } & Female & 82.0 & 82.9 & 83.6 & 83.7 & \\
\hline & Male & 76.4 & 75.2 & 75.1 & 75.5 & \\
\hline \multirow{2}{*}{ Age } & Younger than 40 & 78.5 & 78.3 & 78.3 & 79.2 & \\
\hline & Older than 40 & 79.0 & 78.9 & 79.5 & 79.2 & \\
\hline \multirow{3}{*}{$\begin{array}{l}\text { Education } \\
\text { levels }\end{array}$} & Finished education at the age of 15 & 70.8 & na. & 71.8 & 71.2 & \\
\hline & Finished education between the age of 16 to 19 & 77.9 & na. & 77.0 & 76.7 & \\
\hline & Finished education at an older age than 20 & 86.1 & na. & 84.8 & 84.5 & \\
\hline \multirow{5}{*}{$\begin{array}{l}\text { Type of } \\
\text { contract }\end{array}$} & An indefinite contract & 79.6 & 78.8 & 79.4 & 79.7 & \\
\hline & A fixed term contract & 75.7 & 78.3 & 79.3 & 78.5 & \\
\hline & A temporary employment agency contract & 71.6 & 77.1 & 73.7 & 73.7 & \\
\hline & An apprenticeship or other training scheme & 76.5 & 75.0 & 76.3 & 78.4 & \\
\hline & Other & 77.6 & 77.6 & 76.8 & 78.5 & \\
\hline \multirow{9}{*}{ Occupation } & Legislators, senior officials and managers & 85.1 & 85.8 & 84.6 & 84.9 & \\
\hline & Professionals & 87.8 & 88.4 & 87.7 & 87.0 & \\
\hline & Technicians and associate professionals & 85.7 & 84.7 & 85.0 & 86.6 & \\
\hline & Clerks & 87.3 & 88.4 & 87.5 & 86.2 & \\
\hline & $\begin{array}{l}\text { Service workers and shop and market sales } \\
\text { workers }\end{array}$ & 82.5 & 82.0 & 82.3 & 82.2 & \multirow{5}{*}{$\downarrow$} \\
\hline & Skilled agricultural and fishery workers & 64.0 & 62.7 & 61.8 & 63.9 & \\
\hline & Craft and related trades workers & 66.1 & 64.0 & 60.2 & 61.9 & \\
\hline & Plant and machine operators and assemblers & 65.4 & 63.8 & 65.1 & 66.0 & \\
\hline & Elementary occupations & 72.7 & 71.7 & 74.2 & 72.6 & \\
\hline
\end{tabular}

Directional arrows record that the trend is statistically significant at the 5\% level, and that the change is "substantive", that is, at least 3 points. 
Table 2d. Working Time Quality Gaps by Gender, Age, Contract Type, and Occupational Group.

\begin{tabular}{|c|c|c|c|c|c|c|}
\hline $\begin{array}{l}\text { Socio- } \\
\text { economic } \\
\text { groups }\end{array}$ & Categories & 1995 & 2000 & 2005 & 2010 & Change \\
\hline \multirow{2}{*}{ Gender } & Female & 69.3 & 71.0 & 72.4 & 73.2 & $\uparrow$ \\
\hline & Male & 57.7 & 60.8 & 62.3 & 63.7 & $\uparrow$ \\
\hline \multirow{2}{*}{ Age } & Younger than 40 & 63.1 & 65.6 & 66.8 & 68.2 & $\uparrow$ \\
\hline & Older than 40 & 61.8 & 64.6 & 66.7 & 67.9 & $\uparrow$ \\
\hline \multirow{3}{*}{$\begin{array}{l}\text { Education } \\
\text { levels }\end{array}$} & Finished education at the age of 15 & 58.5 & na. & 64.1 & 64.8 & $\uparrow$ \\
\hline & Finished education between the age of 16 to 19 & 63.2 & na. & 66.6 & 67.6 & $\uparrow$ \\
\hline & Finished education at an older age than 20 & 64.5 & na. & 67.5 & 68.4 & $\uparrow$ \\
\hline \multirow{5}{*}{$\begin{array}{l}\text { Type of } \\
\text { contract }\end{array}$} & An indefinite contract & 66.3 & 68.1 & 69.9 & 70.2 & $\uparrow$ \\
\hline & A fixed term contract & 66.0 & 69.8 & 68.3 & 70.9 & $\uparrow$ \\
\hline & A temporary employment agency contract & 68.7 & 72.5 & 71.7 & 72.5 & $\uparrow$ \\
\hline & An apprenticeship or other training scheme & 68.4 & 70.3 & 69.9 & 73.4 & $\uparrow$ \\
\hline & Other & 65.3 & 70.7 & 69.4 & 70.9 & $\uparrow$ \\
\hline \multirow{9}{*}{ Occupation } & Legislators, senior officials and managers & 49.1 & 51.1 & 52.0 & 55.0 & $\uparrow$ \\
\hline & Professionals & 66.5 & 67.7 & 69.5 & 68.3 & \\
\hline & Technicians and associate professionals & 67.2 & 66.8 & 72.3 & 72.6 & $\uparrow$ \\
\hline & Clerks & 72.4 & 75.4 & 75.6 & 76.3 & $\uparrow$ \\
\hline & $\begin{array}{l}\text { Service workers and shop and market sales } \\
\text { workers }\end{array}$ & 59.8 & 62.1 & 63.7 & 65.5 & $\uparrow$ \\
\hline & Skilled agricultural and fishery workers & 48.2 & 48.1 & 47.3 & 58.1 & $\uparrow$ \\
\hline & Craft and related trades workers & 59.9 & 64.5 & 65.5 & 67.3 & $\uparrow$ \\
\hline & Plant and machine operators and assemblers & 58.8 & 63.0 & 61.8 & 61.8 & $\uparrow$ \\
\hline & Elementary occupations & 66.1 & 71.6 & 70.9 & 73.3 & $\uparrow$ \\
\hline
\end{tabular}

Directional arrows record that the trend is statistically significant at the 5\% level, and that the change is "substantive", that is, at least 3 points. 
Table 3a The Distribution of Work Quality by Country in the EU15, 1995-2010.

\begin{tabular}{|c|c|c|c|c|c|c|}
\hline Country & Statistic & 1995 & 2000 & 2005 & 2010 & Change \\
\hline Austria & Mean & 58.1 & 61.9 & 64.9 & 64.2 & $\uparrow$ \\
\hline Belgium & Mean & 59.0 & 59.8 & 64.7 & 64.2 & $\uparrow$ \\
\hline Denmark & Mean & 69.7 & 70.7 & 72.8 & 75.0 & $\uparrow$ \\
\hline Finland & Mean & 70.1 & 68.4 & 71.0 & 73.2 & $\uparrow$ \\
\hline France & Mean & 60.1 & 58.4 & 61.6 & 58.2 & \\
\hline Germany & Mean & 60.5 & 59.5 & 57.9 & 60.6 & \\
\hline Greece & Mean & 48.2 & 46.8 & 52.6 & 53.0 & $\uparrow$ \\
\hline Ireland & Mean & 57.4 & 57.4 & 62.7 & 62.7 & $\uparrow$ \\
\hline Italy & Mean & 57.5 & 55.3 & 58.0 & 58.0 & \\
\hline Luxembourg & Mean & 58.4 & 57.5 & 66.1 & 66.8 & $\uparrow$ \\
\hline Netherlands & Mean & 70.0 & 71.6 & 69.5 & 69.7 & \\
\hline Portugal & Mean & 53.5 & 46.3 & 54.4 & 56.0 & \\
\hline Spain & Mean & 52.7 & 51.9 & 50.5 & 56.5 & $\uparrow$ \\
\hline Sweden & Mean & 69.0 & 67.5 & 73.8 & 71.5 & \\
\hline United Kingdom & Mean & 69.4 & 64.9 & 59.9 & 64.9 & $\downarrow$ \\
\hline Austria & Gini & 0.228 & 0.21 & 0.217 & 0.209 & \\
\hline Belgium & Gini & 0.206 & 0.225 & 0.201 & 0.216 & \\
\hline Denmark & Gini & 0.151 & 0.155 & 0.143 & 0.135 & \\
\hline Finland & Gini & 0.165 & 0.181 & 0.162 & 0.16 & \\
\hline France & Gini & 0.208 & 0.219 & 0.221 & 0.241 & $\uparrow$ \\
\hline Germany & Gini & 0.226 & 0.227 & 0.232 & 0.237 & \\
\hline Greece & Gini & 0.236 & 0.245 & 0.234 & 0.237 & \\
\hline Ireland & Gini & 0.221 & 0.237 & 0.204 & 0.225 & \\
\hline Italy & Gini & 0.198 & 0.22 & 0.222 & 0.217 & \\
\hline Luxembourg & Gini & 0.217 & 0.236 & 0.2 & 0.205 & \\
\hline Netherlands & Gini & 0.178 & 0.171 & 0.165 & 0.175 & \\
\hline Portugal & Gini & 0.218 & 0.263 & 0.231 & 0.237 & \\
\hline Spain & Gini & 0.228 & 0.231 & 0.252 & 0.249 & $\uparrow$ \\
\hline Sweden & Gini & 0.156 & 0.175 & 0.137 & 0.134 & $\downarrow$ \\
\hline United Kingdom & Gini & 0.192 & 0.215 & 0.223 & 0.218 & $\uparrow$ \\
\hline
\end{tabular}

Directional arrows record that the trend in the average level is statistically significant at the $5 \%$ level, and that the change is "substantive", that is, by at least 3 points. For the Gini index an arrow indicates a "substantive" change by at least 0.02 . 
Table 3b The Distribution of Work Intensity by Country in the EU15, 1995-2010.

\begin{tabular}{|c|c|c|c|c|c|c|}
\hline Country & Statistic & 1995 & 2000 & 2005 & 2010 & Change \\
\hline Austria & Mean & 48.8 & 42.9 & 47.6 & 42.1 & $\downarrow$ \\
\hline Belgium & Mean & 33.2 & 37.3 & 42.8 & 40.2 & $\uparrow$ \\
\hline Denmark & Mean & 39.0 & 37.6 & 47.9 & 39.1 & \\
\hline Finland & Mean & 47.1 & 46.7 & 49.6 & 45.9 & \\
\hline France & Mean & 38.4 & 39.5 & 40.5 & 43.0 & $\uparrow$ \\
\hline Germany & Mean & 40.8 & 40.9 & 46.9 & 44.9 & $\uparrow$ \\
\hline Greece & Mean & 40.9 & 43.5 & 50.5 & 48.6 & $\uparrow$ \\
\hline Ireland & Mean & 39.0 & 42.2 & 36.9 & 47.0 & $\uparrow$ \\
\hline Italy & Mean & 34.1 & 39.7 & 41.9 & 40.8 & $\uparrow$ \\
\hline Luxembourg & Mean & 31.4 & 37.6 & 40.6 & 40.8 & $\uparrow$ \\
\hline Netherlands & Mean & 41.8 & 41.3 & 40.3 & 38.5 & $\downarrow$ \\
\hline Portugal & Mean & 36.2 & 31.8 & 40.1 & 31.6 & $\downarrow$ \\
\hline Spain & Mean & 34.2 & 36.2 & 41.2 & 38.0 & $\uparrow$ \\
\hline Sweden & Mean & 43.3 & 47.9 & 48.1 & 45.9 & $\uparrow$ \\
\hline United Kingdom & Mean & 47.3 & 45.0 & 42.5 & 43.6 & $\downarrow$ \\
\hline Austria & Gini & 0.267 & 0.317 & 0.288 & 0.301 & $\uparrow$ \\
\hline Belgium & Gini & 0.393 & 0.336 & 0.306 & 0.331 & $\downarrow$ \\
\hline Denmark & Gini & 0.326 & 0.314 & 0.283 & 0.300 & $\downarrow$ \\
\hline Finland & Gini & 0.280 & 0.272 & 0.268 & 0.275 & \\
\hline France & Gini & 0.365 & 0.355 & 0.340 & 0.338 & $\downarrow$ \\
\hline Germany & Gini & 0.326 & 0.310 & 0.290 & 0.288 & $\downarrow$ \\
\hline Greece & Gini & 0.331 & 0.300 & 0.281 & 0.301 & $\downarrow$ \\
\hline Ireland & Gini & 0.347 & 0.324 & 0.350 & 0.307 & $\downarrow$ \\
\hline Italy & Gini & 0.359 & 0.315 & 0.315 & 0.309 & $\downarrow$ \\
\hline Luxembourg & Gini & 0.379 & 0.326 & 0.332 & 0.324 & $\downarrow$ \\
\hline Netherlands & Gini & 0.313 & 0.291 & 0.307 & 0.307 & \\
\hline Portugal & Gini & 0.351 & 0.357 & 0.337 & 0.383 & $\uparrow$ \\
\hline Spain & Gini & 0.366 & 0.366 & 0.339 & 0.344 & $\downarrow$ \\
\hline Sweden & Gini & 0.295 & 0.266 & 0.250 & 0.261 & $\downarrow$ \\
\hline United Kingdom & Gini & 0.300 & 0.307 & 0.332 & 0.325 & $\uparrow$ \\
\hline
\end{tabular}

Directional arrows record that the trend in the average level is statistically significant at the $5 \%$ level, and that the change is "substantive", that is, by at least 3 points. For the Gini index an arrow indicates a "substantive" change by at least 0.02 . 
Table 3c The Distribution of Good Physical Environment by Country in the EU15, 19952010.

\begin{tabular}{|c|c|c|c|c|c|c|}
\hline Country & Statistic & 1995 & 2000 & 2005 & 2010 & Change \\
\hline Austria & Mean & 77.8 & 80.8 & 78.8 & 80.0 & \\
\hline Belgium & Mean & 82.1 & 81.3 & 80.8 & 79.1 & $\downarrow$ \\
\hline Denmark & Mean & 83.1 & 83.3 & 81.1 & 83.1 & \\
\hline Finland & Mean & 77.2 & 74.4 & 74.7 & 76.0 & \\
\hline France & Mean & 75.9 & 75.3 & 75.9 & 74.3 & \\
\hline Germany & Mean & 81.3 & 81.5 & 79.5 & 80.7 & \\
\hline Greece & Mean & 66.3 & 68.9 & 67.1 & 72.1 & $\uparrow$ \\
\hline Ireland & Mean & 80.5 & 78.9 & 82.6 & 81.4 & \\
\hline Italy & Mean & 82.3 & 80.5 & 80.0 & 79.7 & \\
\hline Luxembourg & Mean & 80.2 & 80.3 & 80.4 & 77.2 & $\downarrow$ \\
\hline Netherlands & Mean & 81.1 & 81.2 & 83.3 & 84.4 & $\uparrow$ \\
\hline Portugal & Mean & 75.2 & 77.5 & 74.0 & 76.8 & \\
\hline Spain & Mean & 75.3 & 72.5 & 75.3 & 77.5 & \\
\hline Sweden & Mean & 79.6 & 78.0 & 78.5 & 78.0 & \\
\hline United Kingdom & Mean & 77.4 & 79.2 & 83.2 & 82.1 & $\uparrow$ \\
\hline Austria & Gini & 0.134 & 0.117 & 0.132 & 0.108 & \\
\hline Belgium & Gini & 0.115 & 0.111 & 0.115 & 0.115 & \\
\hline Denmark & Gini & 0.096 & 0.090 & 0.098 & 0.087 & \\
\hline Finland & Gini & 0.119 & 0.134 & 0.133 & 0.121 & \\
\hline France & Gini & 0.148 & 0.153 & 0.152 & 0.140 & \\
\hline Germany & Gini & 0.117 & 0.117 & 0.119 & 0.108 & \\
\hline Greece & Gini & 0.189 & 0.189 & 0.210 & 0.191 & \\
\hline Ireland & Gini & 0.127 & 0.135 & 0.105 & 0.113 & \\
\hline Italy & Gini & 0.110 & 0.110 & 0.109 & 0.107 & \\
\hline Luxembourg & Gini & 0.132 & 0.140 & 0.128 & 0.149 & \\
\hline Netherlands & Gini & 0.114 & 0.097 & 0.084 & 0.080 & $\downarrow$ \\
\hline Portugal & Gini & 0.142 & 0.137 & 0.128 & 0.120 & $\downarrow$ \\
\hline Spain & Gini & 0.154 & 0.155 & 0.135 & 0.130 & $\downarrow$ \\
\hline Sweden & Gini & 0.108 & 0.112 & 0.100 & 0.100 & \\
\hline United Kingdom & Gini & 0.126 & 0.142 & 0.103 & 0.104 & $\downarrow$ \\
\hline
\end{tabular}

Directional arrows record that the trend in the average level is statistically significant at the $5 \%$ level, and that the change is "substantive", that is, by at least 3 points. For the Gini index an arrow indicates a "substantive" change by at least 0.02 . 
Table 3d The Distribution of Working Time Quality by Country in the EU15, 1995-2010.

\begin{tabular}{|c|c|c|c|c|c|c|}
\hline Country & Statistic & 1995 & 2000 & 2005 & 2010 & Change \\
\hline Austria & Mean & 61.7 & 64.0 & 63.4 & 68.7 & $\uparrow$ \\
\hline Belgium & Mean & 61.2 & 67.1 & 67.1 & 68.7 & $\uparrow$ \\
\hline Denmark & Mean & 73.2 & 74.9 & 73.9 & 73.4 & \\
\hline Finland & Mean & 63.1 & 63.6 & 66.7 & 69.6 & $\uparrow$ \\
\hline France & Mean & 61.0 & 65.1 & 73.0 & 72.3 & $\uparrow$ \\
\hline Germany & Mean & 65.3 & 67.9 & 66.8 & 68.0 & \\
\hline Greece & Mean & 48.7 & 56.7 & 52.1 & 53.0 & \\
\hline Ireland & Mean & 58.8 & 61.4 & 65.0 & 66.8 & $\uparrow$ \\
\hline Italy & Mean & 58.9 & 61.1 & 62.9 & 66.1 & $\uparrow$ \\
\hline Luxembourg & Mean & 60.5 & 64.6 & 67.8 & 67.4 & $\uparrow$ \\
\hline Netherlands & Mean & 70.3 & 73.9 & 73.1 & 73.7 & $\uparrow$ \\
\hline Portugal & Mean & 57.7 & 63.1 & 62.7 & 64.1 & $\uparrow$ \\
\hline Spain & Mean & 59.4 & 60.6 & 62.4 & 67.0 & $\uparrow$ \\
\hline Sweden & Mean & 68.2 & 68.1 & 67.7 & 68.7 & \\
\hline United Kingdom & Mean & 63.8 & 65.3 & 68.3 & 66.9 & $\uparrow$ \\
\hline Austria & Gini & 0.172 & 0.155 & 0.154 & 0.149 & $\downarrow$ \\
\hline Belgium & Gini & 0.202 & 0.163 & 0.152 & 0.146 & $\downarrow$ \\
\hline Denmark & Gini & 0.122 & 0.120 & 0.126 & 0.136 & \\
\hline Finland & Gini & 0.166 & 0.160 & 0.136 & 0.131 & $\downarrow$ \\
\hline France & Gini & 0.176 & 0.170 & 0.124 & 0.134 & $\downarrow$ \\
\hline Germany & Gini & 0.151 & 0.147 & 0.141 & 0.146 & \\
\hline Greece & Gini & 0.282 & 0.223 & 0.274 & 0.273 & \\
\hline Ireland & Gini & 0.219 & 0.207 & 0.197 & 0.177 & $\downarrow$ \\
\hline Italy & Gini & 0.198 & 0.185 & 0.179 & 0.172 & $\downarrow$ \\
\hline Luxembourg & Gini & 0.161 & 0.147 & 0.131 & 0.150 & \\
\hline Netherlands & Gini & 0.138 & 0.119 & 0.126 & 0.148 & \\
\hline Portugal & Gini & 0.214 & 0.184 & 0.187 & 0.173 & $\downarrow$ \\
\hline Spain & Gini & 0.203 & 0.198 & 0.183 & 0.162 & $\downarrow$ \\
\hline Sweden & Gini & 0.111 & 0.123 & 0.118 & 0.134 & $\uparrow$ \\
\hline United Kingdom & Gini & 0.203 & 0.188 & 0.174 & 0.181 & $\downarrow$ \\
\hline
\end{tabular}

Directional arrows record that the trend in the average level is statistically significant at the $5 \%$ level, and that the change is "substantive", that is, by at least 3 points. For the Gini index an arrow indicates a "substantive" change by at least 0.02 . 
Figure 1 Histograms of the distribution of the indices, with their averages and standard deviations.
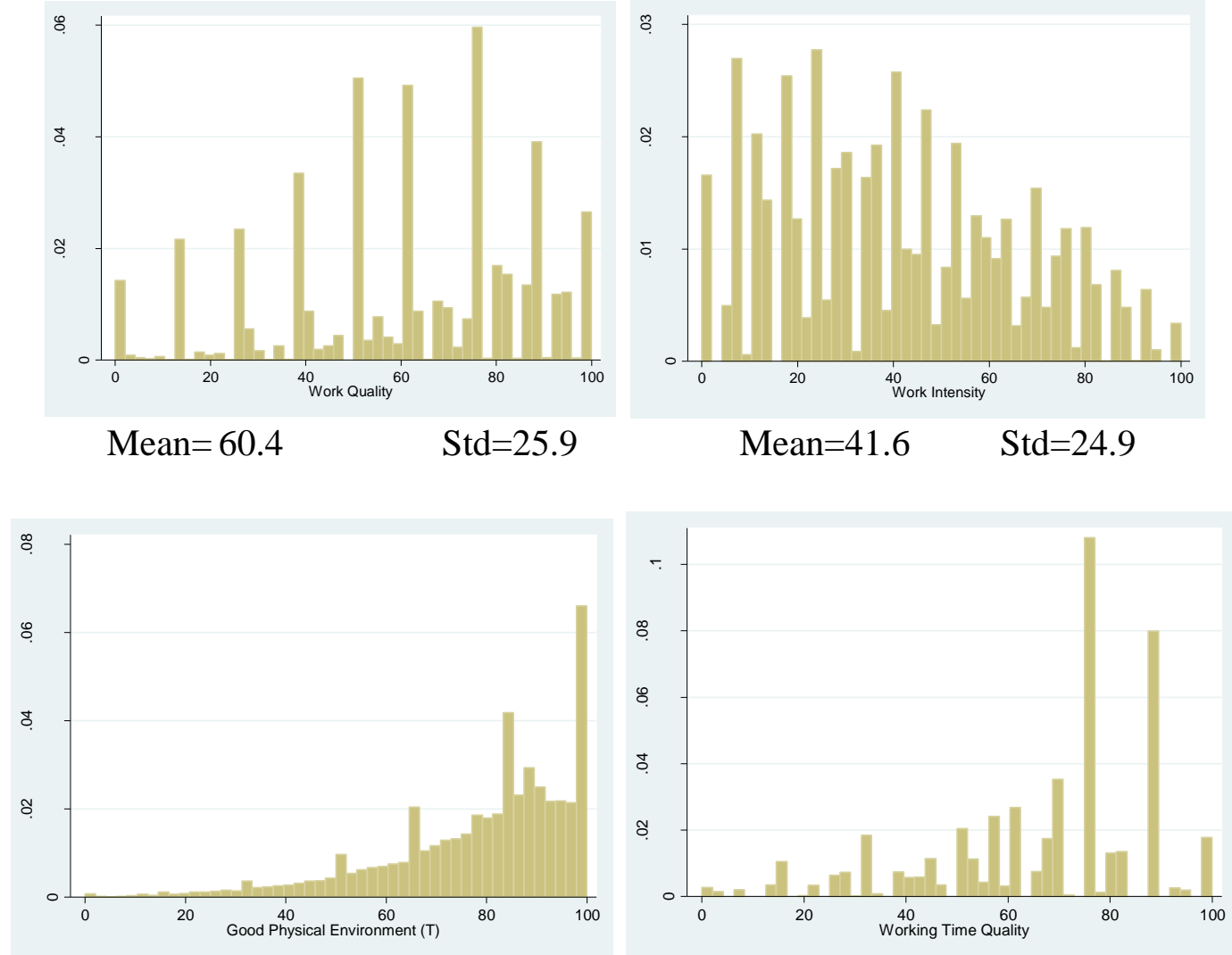

Mean $=78.8 \quad$ Std $=18.8$

Mean $=65.8 \quad$ Std $=20.9$ 
Figure 2. Difference in means between 1995 and 2010.
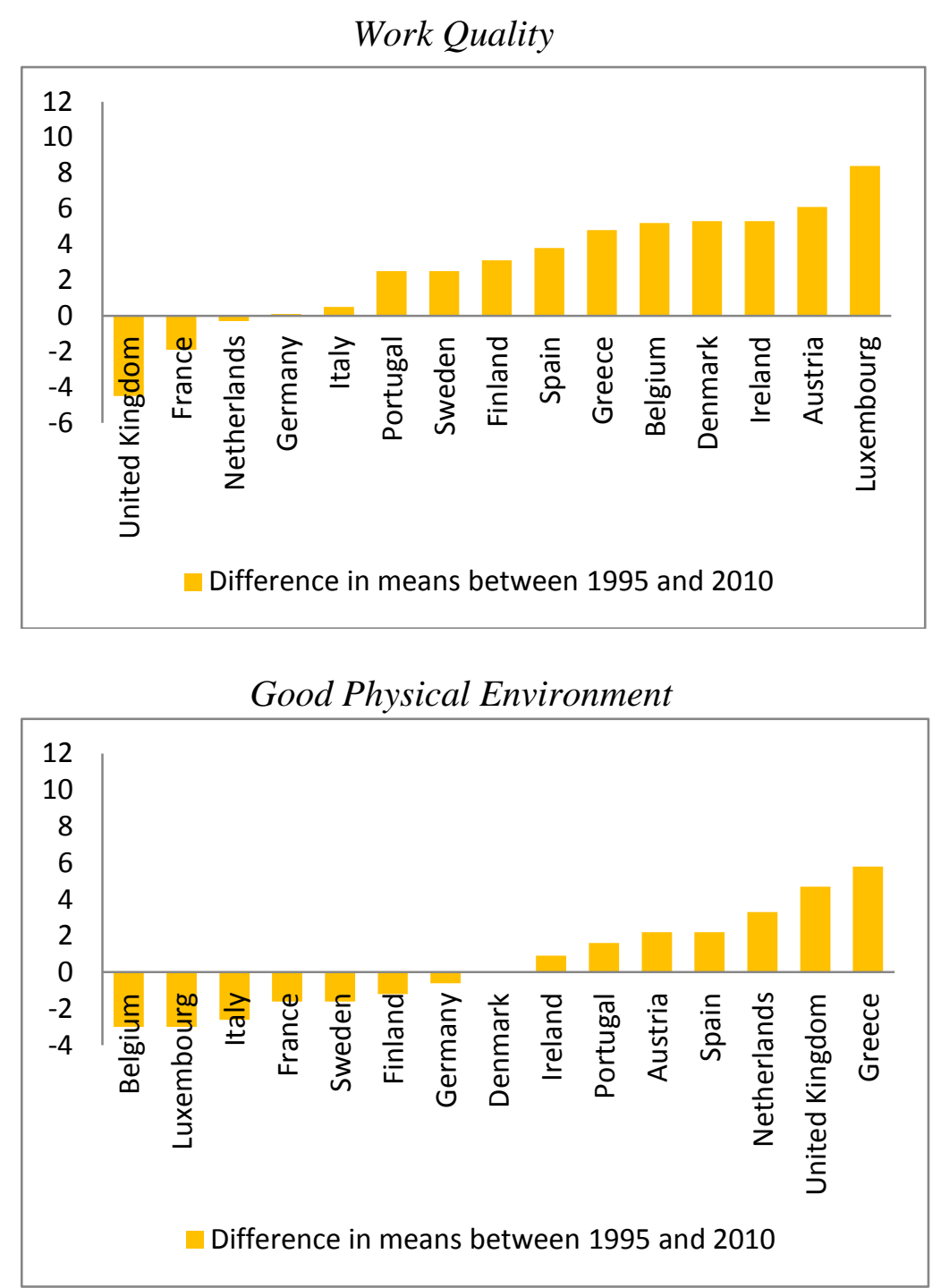

Work Intensity.

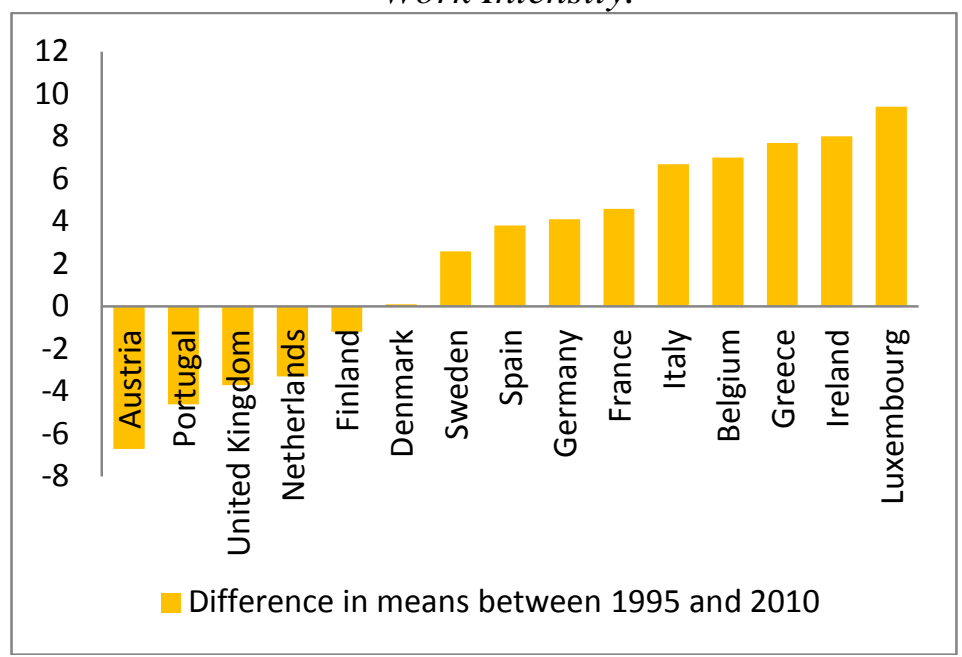

Working Time Quality

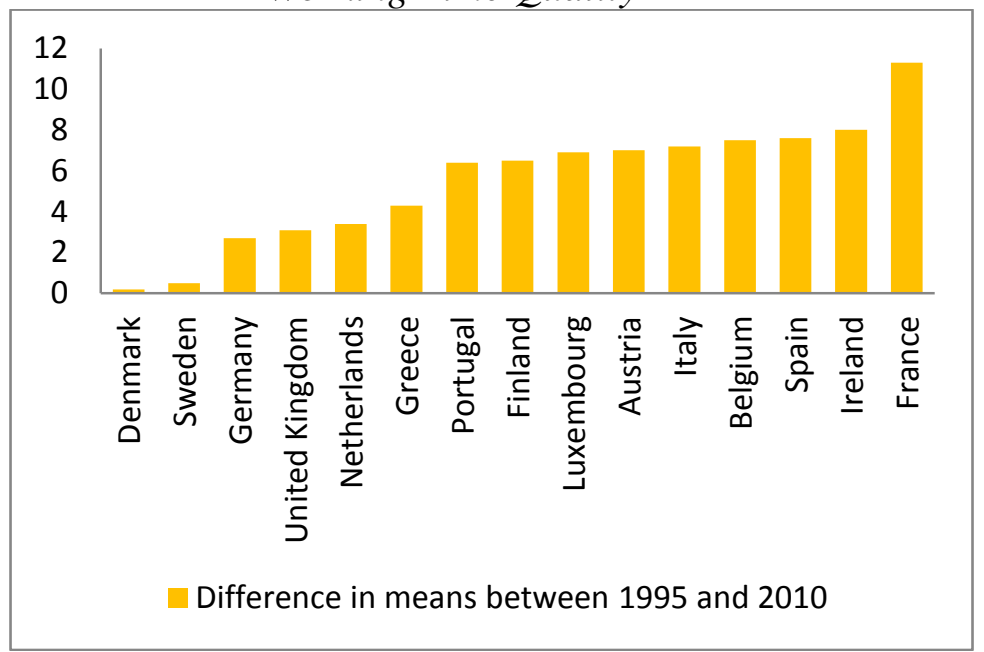


Figure 3. Difference in Gini coefficients between 1995 and 2010.
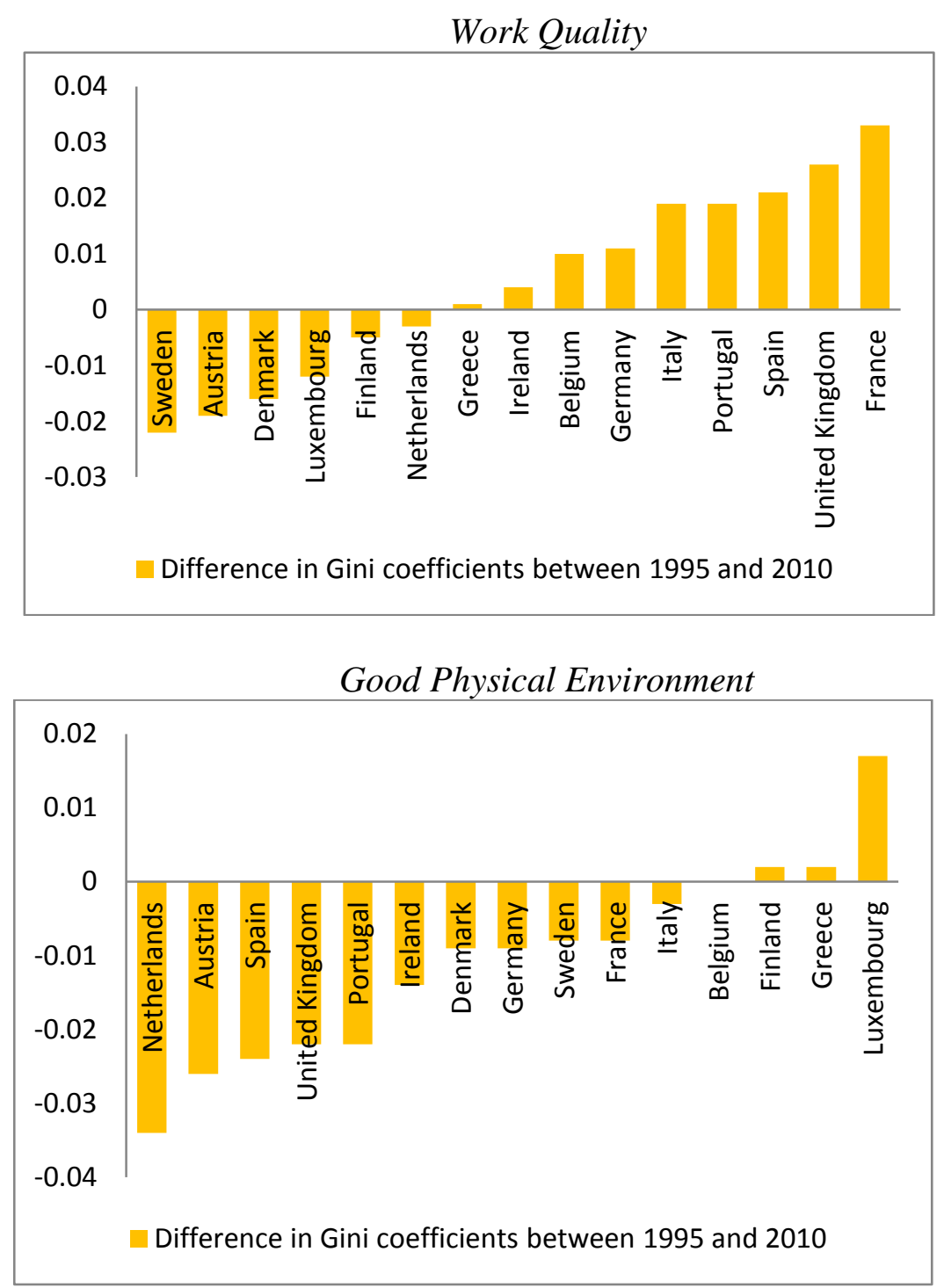

Work Intensity.
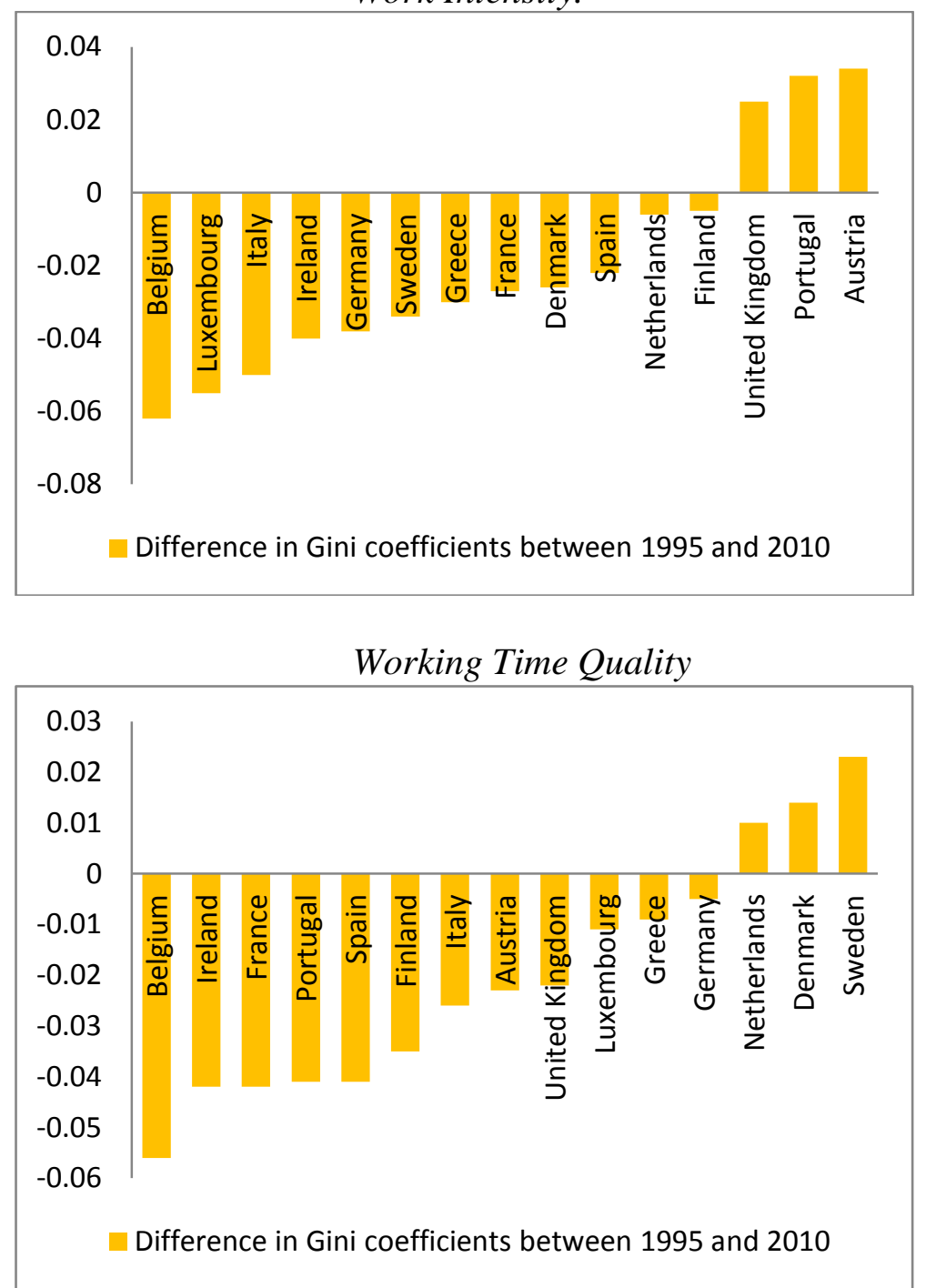